\title{
Carbon Sequestration, Economic Policies and Growth
}

\author{
André Grimaud*and Luc Rouge ${ }^{\dagger}$
}

8th August 2013

${ }^{*}$ Université de Toulouse, Toulouse School of Economics (IDEI and LERNA), Manufacture des Tabacs, 21 Allée de Brienne, 31000 Toulouse, France, and Toulouse Business School. E-mail: grimaud@cict.fr

${ }^{\dagger}$ Corresponding author: Université de Toulouse, Toulouse Business School, 20 Bd Lascrosses, 31068 Toulouse Cedex 7, France. E-mail: l.rouge@esc-toulouse.fr Tel: +335612948 20 Fax: +33 5612949 94 


\begin{abstract}
We present a model of endogenous growth in which the use of a non-renewable resource in production yields $\mathrm{CO}_{2}$ emissions whose accumulated stock negatively affects welfare. A CCS technology enables, via some effort, a partial reduction of these emissions.

We characterize the social optimum and how the availability of CCS technology affects it, and study the trajectories of the decentralized economy. We then analyze economic policies. We first derive the expression of the Pigovian carbon tax and we give a full interpretation of its level, which is unique. We then study the impacts of three different second-best policies: a carbon tax, a subsidy to sequestered carbon, and a subsidy to labor in CCS.

While all three tools foster CCS activity they generally have contrasting effects on resource extraction, carbon emissions, output and consumption. The carbon tax postpones resource extraction whereas the two subsidies accelerate it. Although the tax decreases shortterm carbon emissions, the two subsidies can increase them, thus yielding a green paradox. The tax has a negative impact on the levels of output and consumption in the short-term, unlike the subsidies. The tax generally fosters growth whereas the subsidies reduce it; however, when the weight of the CCS sector in the economy is high, these impacts can be reversed.
\end{abstract}

Keywords: carbon capture and storage (CCS), endogenous growth, polluting nonrenewable resources, carbon tax, subsidy to CCS.

JEL classification: O3, Q3 


\section{Introduction}

The exploitation of fossil resources raises two concerns. The first is scarcity, because fossil resources are exhaustible by nature. The second is related to the emission of greenhouse gases associated with their combustion. Numerous models deal with this double issue; some of them in the context of partial equilibrium (e.g. Sinclair, 1992; Withagen, 1994; Ulph and Ulph, 1994; Hoel and Kverndokk, 1996; Farzin and Tahvonen, 1996; Tahvonen, 1997) and others within general equilibrium growth frameworks (Stollery, 1998; Schou, 2000, 2002; Groth and Schou, 2007; or Grimaud and Rouge, 2008). A common feature of these papers lies in the fact that reducing carbon emissions necessarily means extracting less resource. Indeed, there is generally assumed to be a systematic link between resource extraction and polluting emissions, in the form of a simple functional relation (e.g. linear). In terms of economic policy, it is therefore equivalent to taxing either the pollution stream or the resource use itself. Nevertheless, it is now widely recognized that certain abatement technologies allow the reduction of emissions for a given amount of extracted resource. In particular, attention has recently been focused on the possibility of capturing and sequestering some fraction of the carbon embedded in fossil fuels, whether this capture occurs pre- or post-combustion. This has been reinforced by recent demonstrations of viability (for an overview, see IPCC special report, 2005). This process, often referred to as carbon capture and storage or carbon capture and sequestration (CCS), consists in separating carbon from hydrogen in the pre-combustion process or in separating carbon dioxide from other flux gases in the post-combustion process in an energy production plant. Once captured, the $\mathrm{CO}_{2}$ is injected into a reservoir ${ }^{1}$ for long-term storage. The availability of CCS technologies therefore means that the simple relation between resource extraction and carbon emissions is partially broken.

Here we consider the availability of such an abatement technology in the context of a theoretical general equilibrium model with endogenous growth and a polluting exhaustible resource. We study how the socially optimal trajectories of the economy are modified by the availability of the CCS option, and how the first-best outcome can be restored in a decentralized economy. We also study the impact of three different second-best policies: a carbon tax, a subsidy to sequestered carbon and a subsidy to labor in the CCS activity. Endogenous growth allows us in particular to analyze the effects of the availability of CCS technology and the economic policy tools on growth, along the transition path and at the steady-state.

\footnotetext{
${ }^{1}$ The sequestration reservoirs include depleted oil and gas fields, depleted coal mines, or deep saline aquifers. These various deposits differ in their respective capacities, their costs of access or their effectiveness in storing the carbon permanently.
} 
Numerous uncertainties still surround the large-scale deployment of carbon capture technologies, especially with regard to the ecological consequences of massive carbon injection. The social acceptance of this abatement technique is also uncertain - for a survey on these issues, see for instance Jepma and Hauck (2011). Nevertheless, this technological option has become promising for the fossil energy extractive industry. For instance, Grimaud et al. (2011) show in an empirical model that, insofar as the right climate policy is implemented - a carbon tax in their model -, the percentage of carbon sequestered can exceed $50 \%$.

We develop a Romer-type endogenous growth model in which the production of final good requires the input of an extracted resource, whose stock is available in limited quantities. This resource use generates polluting emissions, which we take to be $\mathrm{CO}_{2}$ emissions, whose flow in turn adds to the pre-existing stock of the pollutant - which features partial natural decay. Finally, this stock enters the utility function as an argument, making it possible to gauge how pollution accumulation negatively affects welfare. Here, we implicitly assume that the economy never reaches a critical level of carbon concentration that would yield an infinitely negative utility (for this type of assumption, see for instance Acemoglu et al., 2012). We then consider that a CCS technology is available. Via some effort, it allows for the partial reduction of the level of $\mathrm{CO}_{2}$ release. We thus distinguish between the total potential $\mathrm{CO}_{2}$ emissions associated with one unit of fossil resource (or equivalently the total carbon content per unit of resource) and the effective emissions, i.e. the fraction that remains after $\mathrm{CO}_{2}$ removal. Note that we do not account for geological $\mathrm{CO}_{2}$ leakage - on this issue, see for instance van der Zwaan and Gerlagh (2009). In this economy, the crucial trade-offs are made between current consumption, future consumption, and current and future environmental quality. We model these trade-offs through the allocation of labor between its alternative uses: output production, R\&D and CCS. This general framework has a straightforward implication in terms of climate policy: the first best outcome can only be restored by taxing pollution, i.e., emissions remaining after sequestration, and not by taxing the resource itself ${ }^{2}$. However, for various reasons, it is likely that the tax cannot be set at its Pigovian level in the real world. Hence, we study second-best policies: a second-best tax on effective carbon emissions, a subsidy to sequestered carbon, and a direct subsidy to labor used in CCS activity. In this second-best world, such complementary policies can improve welfare. This analysis constitutes the main contribution of our paper. We show in particular that it is important to understand how these policies affect the time profile of the

\footnotetext{
${ }^{2}$ Here we assume that the regulator is able to fully measure the greenhouse gas emissions. This may not be systematically the case: while emission data is fairly reliable in industrialized countries, collecting accurate data on industrial activities from developing regions and deducting the emissions may prove more difficult.
} 
total price paid by resource users. This time profile determines the resource extraction path, and hence impacts the paths of CCS activity, carbon emissions, R\&D and output.

We first depict the socially optimal trajectories of the economy, and we study how such trajectories are affected by the availability of the CCS technology. Then we fully characterize the trajectories of the decentralized economy, we derive the expression of the Pigovian carbon tax, and we give a full interpretation of it. In the general case, at the social optimum as well as in the decentralized equilibrium, the economy is always in transition; we nevertheless obtain closedform solutions. This allows us to study the impacts of the three different types of second-best economic policies.

A strand of literature tackles the question of CCS within calibrated empirical models - see for instance Edenhofer et al. (2005); Gerlagh and van der Zwaan (2006); van der Zwaan and Gerlagh (2009); Golombek et al. (2011); Grimaud et al. (2011); or Kalkuhl et al. (2012). The focus of our paper is on the theoretical side of the issue. Several authors have studied the links between carbon abatement, optimal climate policy and technical change in theoretical models. In particular, Goulder and Mathai (2000) show that the presence of induced technical change generally lowers the time profile of optimal carbon taxes. Moreover, efforts in $R \& D$ shift part of the abatement from the present to the future. In a similar framework, Gerlagh et al. (2008) study the link between innovation and abatement policies under certain assumptions, in particular the fact that patents can have a finite lifetime. In these studies, the authors use partial equilibrium frameworks in which baseline $\mathrm{CO}_{2}$ emissions are exogenous, and final (or effective) carbon emissions are endogenous as there is an abatement activity with dedicated technical progress. Hoel and Jensen (2010) show, in a two-period model, that if the climate policy is imperfect - that is, if it can only be implemented in the second period -, cost reductions are more desirable in the CCS than in the renewable sector in particular because they postpone resource extraction.

Many recent contributions take into account the availability of a CCS technology. Most of them consider the context of partial equilibrium frameworks: see for instance Lafforgue et al. (2008), Narita (2009), Amigues et al. (2011) or Rickels (2011). These papers mainly focus on socially optimal issues, and in particular they study the optimal time profile of carbon sequestration. Lontzek and Rickels (2008) and Ayong le Kama et al. (2009) study the same questions, but they also consider a decentralized economy. However, they do not study the impact of economic policies on the decentralized equilibrium. Most of these papers consider a carbon ceiling; in this case, Lafforgue et al. show that CCS is implemented only when the 
ceiling is reached. When the CCS cost function is convex however, as in Rickels, it is optimal to sequester carbon before the ceiling. Similarly, CCS activity has to start in the near term when there is no ceiling but a damage function, as in Ayong le Kama et al. Finally, technical progress is not explicitly considered in these studies.

Our main results can be summarized as follows ${ }^{3}$. At the social optimum, the amount of labor devoted to CCS activity is a constant proportion of resource use; in other words, the CCS effort per unit of carbon content is constant. Since resource use decreases over time, this implies that the abatement effort also decreases: the greatest effort in abatement should happen today $^{4}$ - this contrasts with the result of Lafforgue et al. (2008) mentioned in the previous paragraph. We also show that the availability of CCS technology modifies the socially optimal trajectories of the economy. It speeds up the optimal pace of resource extraction, as it relaxes the environmental constraint. While it diminishes polluting emissions in the long run, it fosters them in the short run when the rise in resource extraction, and thus of potential emissions, is less than proportionally compensated by the CCS activity. Lastly, the availability of such a technology reduces the socially optimal growth of output as a result of the acceleration in resource extraction combined with a negative effect on $R \& D$ effort.

Due to the availability of CCS technology, the Pigovian carbon tax is unique, which contrasts with the standard result obtained in a context without abatement, as in Dasgupta and Heal (1979), Sinclair (1992), Groth and Schou (2007) or Grimaud and Rouge (2008) for instance. In these models, there are an infinity of optimal taxes which have the same dynamics but differ in their levels. Here, the tax level matters, especially for setting the optimal abatement effort level. The optimal carbon tax is equal to both the sum of discounted social costs of one unit of carbon and the cost of sequestering this unit. We study its properties, and we show that, under specific assumptions on preferences and technology, it is proportional to output ${ }^{5}$.

The second-best carbon tax fosters CCS activity and postpones resource extraction. It also lowers short-term $\mathrm{CO}_{2}$ emissions. However, this leads to lower levels of output and consumption

\footnotetext{
${ }^{3}$ We often resort to the distinction between the short and long terms. In a Hotelling world, where the whole stock of resource is asymptotically exhausted, any increase (resp. decrease) in resource extraction at date $t$ generates changes for all subsequent dates. The short term refers to the period during which resource extraction is also increased (resp. decreased), that is, the current period and the near future (i.e, the first few generations), whereas the long term refers to the period during which resource use is consequently decreased (resp. increased), that is, the distant future.

${ }^{4}$ We show that this result can be slightly altered if one expects a high rate of technical progress in CCS technology.

${ }^{5}$ This particular form of the first-best tax can be linked to Golosov et al. (2011) or Gerlagh and Liski (2012). However, since we consider here the possibility of CCS, the tax we study is not levied on resource use but on carbon emissions. As a result, this tax not only reallocates inputs in production, but also induces agents to sequester carbon.
} 
in the short term. The impact of the tax on economic growth is more complex. As polluting emissions stem from the use of non-renewable resources, if no carbon abatement technology were available, a more stringent environmental policy would generally enhance economic growth, since it leads to postponing resource extraction (see for instance Groth and Schou, 2007, or Grimaud and Rouge, 2008). We show that this does not always hold true when CCS technology becomes available. Indeed, if the weight of the CCS sector in the whole economy is high, that is if the CCS sector employs an amount of labor which is significant, this effect can be reversed: the tax can reduce the growth of output and consumption.

The subsidy to sequestered carbon is a perfect substitute for the carbon tax with regard to its impact on CCS activity. However, the effects of the two policy instruments on resource use are opposite: with the subsidy, extraction is faster. A kind of (weak) green paradox can therefore occur here in the sense that this climate policy can increase short-term emissions (on the issue of green paradox in other contexts, see e.g. Sinn, 2008, Gerlagh, 2011, or van der Ploeg and Withagen, 2012). Short-term resource use and carbon abatement being both promoted, this green paradox occurs when the former effect exceeds the latter. The impacts of the subsidy and the tax on short-term output and consumption are also opposite: the subsidy prompts greater output and consumption levels in the early periods. This point should be considered when taking into account public acceptance issues. Indeed, this subsidy could be seen as a good complementary tool to a second-best carbon tax since it alleviates the burden of climate policy in the short term. Finally, the effect of the subsidy on economic growth is basically also opposite to the effect of the tax: the subsidy generally reduces growth, but, if the weight of the CCS sector in the whole economy is high, it can promote long-term growth.

Another result is that the subsidy to labor in CCS alone does not trigger any CCS activity. This tool has an effect only when it is used jointly with a carbon tax or a subsidy to sequestered carbon. In this case, its impact on CCS activity, resource extraction, carbon emissions and the level and growth of output and consumption are similar to those of the subsidy to sequestered carbon.

The remainder of the paper is organized as follows. We present the model and we portray the social optimum in Section 2. We characterize the equilibrium of the decentralized economy in Section 3, and we study the first-best economic policy and the impact of the second-best policies in Section 4. Finally, we conclude in Section 5. 


\section{Model and welfare}

\subsection{The model}

The final good is produced from three types of inputs. The first two ones, intermediate goods and labor, are standard inputs in a Romer-type technology. The third is a flow of energy. Energy is produced from fossil fuels; at each date $t$, the flow of energy is simply modeled through resource use. Here, output production is nil in the absence of fossil fuels, i.e. we do not consider the existence of a backstop ${ }^{6}$. Formally, the final output is produced at each date $t \in[0,+\infty)$ using the range of available intermediate goods, labor and a flow of resource according to the following production function:

$$
Y_{t}=\left(\int_{0}^{A_{t}} x_{i t}^{\alpha} d i\right) L_{Y t}^{\beta} R_{t}^{\gamma}, \alpha+\beta+\gamma=1
$$

where $x_{i t}$ is the amount of intermediate good $i, L_{Y t}$ the quantity of labor employed in the production sector, and $R_{t}$ is the flow of non-renewable resource. $A_{t}$ is a technological index which measures the range of available innovations. The production of innovations is given by

$$
\dot{A}_{t}=\delta L_{A t} A_{t}, \delta>0
$$

where $L_{A t}$ is the amount of labor devoted to research, and $\delta$ is a constant characterizing the efficiency of $R \& D$ activity $^{7}$.

With each available innovation is associated an intermediate good produced from the final output:

$$
x_{i t}=y_{i t}, i \in\left[0, A_{t}\right]
$$

The non-renewable resource is extracted from an initial finite stock $S_{0}$. At each date $t$, a flow $-\dot{S}_{t}$ is extracted. This implies the following standard law of motion:

$$
\dot{S}_{t}=-R_{t}
$$

There are no extraction costs, as it is the case in most endogenous growth models with polluting non-renewable resources (see for instance Schou, 2000, 2002 or Groth and Schou, 2007) ${ }^{8}$.

\footnotetext{
${ }^{6}$ Taking backstop technologies into account would make it possible to study the question of the impact of CCS on the adoption timing of these renewable sources of energy, which is outside the scope of the current study.

${ }^{7}$ Here labor is the only input other than the knowledge stock that appears in the knowledge production function; indeed, it is the variable whose allocation between its different uses will embody the basic arbitrages of the economy. For other assumptions on knowledge production in a growth model with climate change see for instance Popp (2006).

${ }^{8}$ This avoids heavy computational complexity. For general optimal solutions when faced with extraction costs as studied André and Smulders (2004) in a model with no abatement, see for instance Grimaud and Rouge (2008).
} 
Pollution is generated by the use of the non-renewable resource within the production process. In case of no abatement, the pollution flow would be a linear function of resource use: $h R_{t}$, where $h>0$. In this way, $h R_{t}$ can be seen as the carbon content of resource extraction or, equivalently, as maximum potential emissions at time $t$. Nevertheless, firms can abate part of this carbon so that the actual emitted flow of pollution is

$$
P_{t}=h R_{t}-Q_{t}
$$

where $Q_{t}$ is the amount of carbon that is removed from the potential emission flow. The ratio $P_{t} / h R_{t}$ thus represents the effective emissions per unit of carbon content at date $t$, that is, the quantity of carbon actually emitted in the atmosphere relative to the carbon that would be emitted with the same extraction level but without the CCS option. $Q_{t} / h R_{t}$ is the rate of sequestration, that is, the amount of sequestered carbon relative to the total carbon content of the flow $R_{t}$ of extracted resource.

We assume that $Q_{t}$ is produced from two inputs, the pollution content $h R_{t}$ and dedicated labor $L_{Q t}$, according to the following Cobb-Douglas abatement technology ${ }^{9}$ :

$$
Q_{t}=\left(h R_{t}\right)^{\eta} L_{Q t}^{1-\eta}, 0<\eta<1, \text { if } L_{Q t}<h R_{t}
$$

and

$$
Q_{t}=h R_{t}, \text { if } L_{Q t} \geq h R_{t},
$$

that is, the pollution flow is fully abated once $L_{Q t}=h R_{t}{ }^{10}$. The ratio $L_{Q t} / h R_{t}$ represents the CCS effort, i.e. the amount of labor devoted to this activity, per unit of carbon content. The Cobb-Douglas form allows simple analytical developments. For any given $h R_{t}$, the total cost of labor, $L_{Q t}=Q_{t}^{1 /(1-\eta)}\left(h R_{t}\right)^{-\eta /(1-\eta)}$, is an increasing and convex function of $Q_{t}$. The marginal and average labor costs, respectively $\partial L_{Q t} / \partial Q_{t}=[1 /(1-\eta)] Q_{t}^{\eta /(1-\eta)}\left(h R_{t}\right)^{-\eta /(1-\eta)}$ and $L_{Q t} / Q_{t}=Q_{t}^{\eta /(1-\eta)}\left(h R_{t}\right)^{-\eta /(1-\eta)}$, are also increasing functions of $Q_{t}$. Given any quantity of potentially emitted carbon $h R_{t}$, it is the effort in terms of labor only that enables pollution

\footnotetext{
Using data on the prices of fossil fuels over the last century, Gaudet (2007) shows that, despite high volatility, these prices remained approximatively constant, or at most increased only slightly.

${ }^{9}$ More generally, one could consider the technology $Q_{t}=\left(h R_{t}\right)^{\eta}\left(\xi L_{Q t}\right)^{1-\eta}, 0<\eta<1$, if $L_{Q t}<h R_{t} / \xi$ and $Q_{t}=h R_{t}$, if $L_{Q t} \geq h R_{t} / \xi$, with $\xi>0$. Here, we normalize $\xi$ at one. Other abatement technologies can be found in Stokey (1998), Copeland and Taylor (2004) or Aghion and Howitt (1998). In the latter, output is an increasing function of a technological index, and the pollution flow is an increasing function of the output level and of this index. However, there are two main differences here. First, pollution is a by-product of the resource use, and not of output; second, pollution can be abated by using more labor - and not through a different technological index.

${ }^{10}$ In the following sections, we make an assumption on parameters so that this corner solution never occurs.
} 
abatement. In a calibrated model, which is outside the scope of the current analysis, introducing capital in the technology (6) would certainly improve the framework by making it more realistic - the same applies for production functions (1) or (2). Here, in the context of a theoretical analysis, this would highlight an arbitrage between CCS and future consumption (through capital accumulation and thus future production). In fact, this arbitrage is already present in our framework: it is modeled by the allocation of labor between CCS $\left(L_{Q}\right)$ and research $\left(L_{A}\right)$ moreover, this would add a fourth state variable, which would make our computations much more complex. Finally, note that, for the sake of simplicity, contrary to Goulder and Mathai (2000) or Gerlagh et al. (2008) for instance, we do not consider technical progress in abatement ${ }^{11}$. We also assume away storage constraints ${ }^{12}$.

At each date $s \in(0 ; t)$, the flow of resource use $R_{s}$ yields after sequestration a flow of carbon emissions $P_{s}$ that adds to the existing stock. However, we take natural removal into account: $P_{s} e^{\theta(s-t)}$ is the fraction of $P_{s}$ that still remains in the atmosphere at date $t$, where $\theta>0$ is the exponential rate of natural removal. Hence the total stock of carbon at date $t$ is $Z_{t}=Z_{0}+\int_{0}^{t} P_{s} e^{\theta(s-t)} d_{s}$, where $Z_{0}>0$ is the initial level of the stock of carbon - which one can see as its pre-industrial level. Differentiating $Z_{t}$ with respect to time yields the law of motion of the carbon stock:

$$
\dot{Z}_{t}=P_{t}+\theta\left(Z_{0}-Z_{t}\right)
$$

Thus, at each date $t$, the stock of carbon $Z_{t}$ increases by the flow of carbon emissions $P_{t}$ and decreases by the natural removal $\theta\left(Z_{0}-Z_{t}\right)^{13}$.

Production flow $Y_{t}$ is used for consumption $\left(C_{t}\right)$ and for the production of intermediate goods:

$$
Y_{t}=C_{t}+\int_{0}^{A_{t}} y_{i t} d i
$$

Population is assumed constant, normalized at one, and each individual is endowed with one

\footnotetext{
${ }^{11}$ Such an assumption would be more realistic. For instance, one can consider the function $Q_{t}=$ $\left(h R_{t}\right)^{\eta}\left(A_{Q t} L_{Q t}\right)^{1-\eta}$, where $A_{Q t}$ grows over time at exogenous rate. However, in this endogenous growth framework, it would make our computations much more complex. We nevertheless show later in the text how such a formulation can generalize certain results of our paper.

${ }^{12}$ At the local scale, such constraints can be important, especially when transportation costs are non-negligible (on this issue, see for instance Lafforgue et al., 2008, in a partial equilibrium framework). Here, we implicitly assume that carbon sinks are large enough to store any stock of $\mathrm{CO}_{2}$.

${ }^{13}$ This formulation is standard in the literature. As Goulder and Mathai (2000) or Gerlagh et al. (2008) point out, the dynamics of the stock of carbon are more complex in reality. To make equation (7) more realistic, we could consider a non constant rate of decay, for instance. However, such a formulation would make the model much less tractable. We could also add a short-term natural removal rate to the flow of emissions, as in Nordhaus (1994) or Goulder and Mathai (2000) in the numerical part of their study. However, this would not change the results of our analysis.
} 
unit of labor. We have:

$$
1=L_{Y t}+L_{A t}+L_{Q t}
$$

The key trade-offs in this model are thus characterized through the allocation of labor between the three activities, production, research and sequestration. For this reason, despite the absence of capital in our framework (in particular in equations (1), (2) and (6)) we are able to consider the basic arbitrages between current consumption, future consumption, and current and future environmental quality.

The household's instantaneous utility function depends on both consumption, $C_{t}$, and the stock of $\mathrm{CO}_{2}, Z_{t}$. The intertemporal utility function is:

$$
U=\int_{0}^{+\infty}\left[\ln C_{t}-\omega Z_{t}\right] e^{-\rho t} d t, \rho>0 \text { and } \omega \geq 0
$$

The separability of the utility function simplifies the computations. This means that, though the impact of a change in the pollution stock on the marginal utility of consumption could be considered positive or negative, we take it as nil. Here, a given increase in the carbon concentration harms households in the same way, regardless of the current consumption level. Equivalently, this means that the carbon stock has no impact on the marginal utility of consumption. Concerning environmental preferences, as Goulder and Mathai (2000) observe, the damage function can be regarded as convex or concave; we simply consider a linear relationship. In other words, the disutility generated by a given flow of carbon is independent of the current concentration level. As we will see, such properties of the utility function condition the form of the ratio $L_{Q t} / h R_{t}$, which is crucial in our analysis, as well as the expression of the first-best carbon tax.

\subsection{Welfare analysis}

\subsubsection{Social optimum}

We now present the socially optimal trajectories of the economy. The social planner maximizes $U=\int_{0}^{+\infty}(\ln C-\omega Z) e^{-\rho t} d t$ subject to (1)-(9). The planned economy is always in transition; however, we obtain closed-form solutions. All computations and results are given in Appendix 1, where we fully depict the socially optimal transition time-paths of all variables. In this section, we focus only on the most relevant trade-offs. Hereafter, we denote by $g_{X t}=\dot{X}_{t} / X_{t}$ the growth rate of any variable $X_{t}$, and by $X_{t}^{o}$ its socially optimal level. 
We obtain

$$
L_{Q t}^{o}=\left[\frac{\rho \omega(1-\eta)}{\delta(\rho+\theta)}\right]^{1 / \eta} h R_{t}^{o}
$$

Thus the ratio $L_{Q t}^{o} / h R_{t}^{o}$ is constant, which implies $Q_{t}^{o} / h R_{t}^{o}$ and $P_{t}^{o} / h R_{t}^{o}$ constant. We now explain where this result comes from - we will see that, in particular, it depends on the functional forms we have chosen for CCS, carbon accumulation in the atmosphere and utility. It should be first remembered that, in this model, the main trade-offs are characterized through the allocation of labor between its three competing uses: production $\left(L_{Y}\right)$, research $\left(L_{A}\right)$ and CCS $\left(L_{Q}\right)$. The social planner allocates labor between these sectors so that a marginal increase in this input in any sector yields the same variation of intertemporal utility. On the one hand, $\Delta L_{Q t}^{o}=1$ yields an increase in $Q_{t}$ and thus a decrease in pollution $P_{t}: \Delta P_{t}=-\Delta Q_{t}=$ $-(1-\eta)\left(h R_{t} / L_{Q t}\right)^{\eta}$, from (5) and (6). $\Delta P_{t}$ is a linear function of $\left(h R_{t} / L_{Q t}\right)^{\eta}$; it stems from the fact that the CCS technology (6) is Cobb-Douglas, homogeneous of degree 1, which implies that the partial derivatives are homogeneous of degree 0 and thus only depend on the inputs ratio. By assumption, we have $Z_{t}=Z_{0}+\int_{0}^{t} P_{s} e^{\theta(s-t)} d_{s}$, thus $\Delta Z_{v}=\Delta P_{t} e^{\theta(t-v)}=-(1-$ $\eta)\left(h R_{t} / L_{Q t}\right)^{\eta} e^{\theta(t-v)}$ for all $v \geq t$. Finally, using (10), we have $\Delta_{1} U_{t}=-\int_{t}^{+\infty} \omega \Delta Z_{v} e^{-\rho(v-t)} d v=$ $\omega(1-\eta)\left(h R_{t} / L_{Q t}\right)^{\eta} /(\rho+\theta)$. The fact that $\Delta_{1} U_{t}$ is a linear function of $\left(h R_{t} / L_{Q t}\right)^{\eta}$ stems from the fact that the rate of $\mathrm{CO}_{2}$ natural decay $\theta$ is constant and utility is separable and linear in $Z_{t}$. On the other hand, we show in Appendix 1 (Section i) that $\Delta L_{A t}^{o}=1$ yields $\Delta_{2} U_{t}=\delta / \rho$. Basically, two main assumptions made in the present framework explain that $\Delta_{2} U_{t}$ is constant: the production of knowledge exhibits constant marginal returns to labor (equation (2)) and utility is separable and logarithmic in consumption (equation (10)). Finally, we also show in Appendix 1 that $\Delta L_{Y t}^{o}=1$ yields $\Delta_{3} U_{t}=\beta /(1-\alpha) L_{Y t}$. Here, the form of $\Delta_{3} U_{t}$ stems from the decreasing marginal returns to labor in the output production function (equation (1)), and, here also, the separable utility function, logarithmic in consumption. By equalizing $\Delta_{2} U_{t}$ and $\Delta_{3} U_{t}$, we obtain $L_{Y}^{o}=\beta \rho / \delta(1-\alpha)$. By equalizing $\Delta_{1} U_{t}$ and $\Delta_{2} U_{t}$, we get equation (11).

We also have

$$
R_{t}^{o}=\frac{\gamma}{\chi_{0} e^{\rho t}+B}
$$

in which $\chi_{0}=B /\left(e^{\frac{B \rho S_{0}}{\gamma}}-1\right)$ and $B=\frac{(1-\alpha) \omega h}{\rho+\theta}\left[1-\eta\left(\frac{\rho \omega(1-\eta)}{\delta(\rho+\theta)}\right)^{(1-\eta) / \eta}\right]$. Moreover, we get

$$
g_{R t}^{o}=g_{L_{Q t}}^{o}=g_{Q_{t}}^{o}=g_{P_{t}}^{o}=\frac{-\rho}{1+\left(e^{\frac{B \rho S_{0}}{\gamma}}-1\right) e^{-\rho t}} .
$$


As shown in Appendix 1 (Section iv), since $B>0, g_{R t}^{o}<0$ for all $t . L_{Q t}^{o} / h R_{t}^{o}$ being constant, this means that $L_{Q t}^{o}$ decreases over time. In other words, the greatest effort in CCS is required today: the social planner places the strongest sequestration efforts in the short run and diminishes them progressively over time.

Finally, the socially optimal growth rate of the economy is

$$
g_{Y t}^{o}=g_{A t}^{o}+(\gamma /(1-\alpha)) g_{R t}^{o} .
$$

Remark: Suppose now that there is technical progress in the CCS function - as in e.g. Gerlagh and van der Zwaan (2006). For instance, assume $Q_{t}=\left(h R_{t}\right)^{\eta}\left(A_{Q t} L_{Q t}\right)^{1-\eta}$, where $A_{Q t}$ grows over time at an exogenous rate. In this case, equation (11) becomes $L_{Q t}^{o} / h R_{t}^{o}=$ $[\rho \omega(1-\eta) / \delta(\rho+\theta)]^{1 / \eta} A_{Q t}^{(1-\eta) / \eta}$, and we get $Q_{t}^{o} / h R_{t}^{o}=[\rho \omega(1-\eta) / \delta(\rho+\theta)]^{(1-\eta) / \eta} A_{Q t}^{(1-\eta)^{2} / \eta}$. Then, if technical progress in CCS is high, $L_{Q t}^{o}$ and $Q_{t}^{o}$ increase over time. In other words, the socially optimal effort in CCS can increase over some intervals of time. As mentioned above, our basic model does not feature technical progress in CCS because it would make our computations much more complex.

Finally, the economy tends asymptotically to a steady-state which corresponds to the state the economy would immediately jump to if environmental preferences were nil $(\omega=0)$.

\subsubsection{Impact of CCS on the socially optimal trajectories}

We have just seen that the socially optimal effort in CCS is strictly positive (see equation (11)). This means that the availability of CCS technology increases social welfare. In order to study the impact of carbon abatement on the socially optimal paths, we consider the social optimum in the case where CCS technology is not available. We denote by $X_{t}^{o \varnothing}$ the optimal level of any variable $X_{t}$ in this case, with $X_{t}^{o}$ still standing for the optimal value in the CCS case. We provide the optimal levels and growth rates in the no-CCS case in Appendix 2. If we now compare the optimal growth rates of resource extraction in the two cases, we obtain the following inequality:

$$
g_{R t}^{o}<g_{R t}^{o \varnothing}
$$

The literature shows that laissez-faire resource extraction is too fast (see for instance Withagen, 1994), and thus that $g_{R}$ is too low. The above inequality shows that if CCS technology is available, the optimal extraction is faster than in the absence of such a technology and thus less 
restrictive. In other words, more resource is used in the short run and less in the long run. For this reason, one can say that CCS partially relaxes the environmental constraint; the sacrifice required in the early periods is reduced.

The impact of CCS on the optimal pollution paths is less obvious. We first consider the near term. Two opposite effects drive the pollution path. First, $h R_{t}^{o \varnothing}<h R_{t}^{o}$, that is, potential emissions are increased. Indeed, since resource extraction is increased, carbon emissions tend to rise as well. At the same time, CCS activity reduces pollution. However, such an activity has a cost in terms of knowledge accumulation (see equations (9) and (2)), and thus in terms of future output and consumption. This means that the short-run level of sequestered carbon can be low, that is, not high enough to compensate for the rise in resource extraction. In such a case, the introduction of CCS technology entails a rise in the socially optimal level of polluting emissions in the short term ${ }^{14}$. In the long term, CCS unambiguously induces lower emissions. Indeed, we have shown that extraction decreases; thus, whatever the amount of sequestered carbon, pollution decreases.

We now turn to the effect of CCS on optimal growth. First, $L_{Q t}^{o \varnothing}$ and $Q_{t}^{o \varnothing}$ are obviously nil. Moreover, $L_{Y}^{o}=L_{Y}^{o \varnothing}=\beta \rho / \delta(1-\alpha)$ (as shown in Appendix 1 and Appendix 2). This implies $L_{A t}^{o}<L_{A t}^{o \varnothing}$ : the amount of labor devoted to $R \& D$ is lower in the "CCS case" as CCS is a third competing use for labor. So there is a first effect on research which reduces growth - such a mechanism also occurs in growth models with renewable resources, as in Smulders and Gradus (1996) for instance. Here, it is reinforced by an additional mechanism which we have presented above: resource extraction is faster $\left(g_{R t}^{o}<g_{R t}^{o \varnothing}\right)$. Thus, we have the following inequality: $g_{Y t}^{o}=\delta L_{A t}^{o}+(\gamma /(1-\alpha)) g_{R t}^{o}<g_{Y t}^{o \varnothing}=\delta L_{A t}^{o \varnothing}+(\gamma /(1-\alpha)) g_{R t}^{o \varnothing}$. In other words, CCS reduces economic growth, because of the lower effort in $R \& D$ and the acceleration of resource extraction.

Finally, CCS increases consumption levels in the early stages. As shown in Appendix 1 (Section i), consumption is a linear function of output. We have seen that the amount of labor in production remains unchanged by the introduction of CCS technology and that resource extraction is increased in the near term. If we consider a sufficiently short period of time during which the reduced growth of knowledge does not offset these two effects, then the production level increases. Hence, the optimal short-run consumption levels are greater in an economy with CCS.

\footnotetext{
${ }^{14}$ This result can be related to Goulder and Mathai (2000), in which a more efficient abatement technology leads to higher pollution levels in the short-run. However, baseline emissions are exogenous in their model, and pollution rises because abatement falls.
} 


\section{Decentralized Economy}

We now study the equilibrium trajectories of the decentralized economy, which will enable us to study the impacts of climate policies in the following section. Since we study a Romer model, there are two first basic distortions: the standard public good character of knowledge and the monopolistic structure of the intermediate sector. A third distortion arises from polluting emissions whose accumulated stock harms welfare. In order to correct these distortions, we introduce three economic policy tools: a unit subsidy to the use of intermediate goods, a research subsidy and a tax on polluting emissions. Note that climate policy does not consist of a tax on the polluting resource, as in Groth and Schou (2007) or Grimaud and Rouge (2008). The basic externality is polluting emissions and, as an abatement technology is available, a tax on these emissions and a tax on the polluting resource are not equivalent. The latter tax would only modify the extraction path and would have no impact on CCS activity. Conversely, as we will show below, the tax on carbon emissions has two main effects: it leads to postponing extraction (as in models without abatement) and it provides incentives to produce optimal efforts in carbon abatement at each date $t$.

For many reasons, e.g. lack of international political consensus, it is not always possible to implement a carbon tax at the Pigovian level. Hence we consider two additional economic policy tools aimed at -partially- compensating, in a second-best world, the fact that the carbon tax cannot be set at its first-best level. The first is a subsidy to sequestered carbon ${ }^{15}$. The second is a subsidy to labor devoted to CCS, which can be considered as observable as sequestered carbon.

\subsection{Agents' behavior}

The price of the final good is normalized at one, and $w_{t}, p_{i t}, p_{R t}$, and $r_{t}$ are, respectively, the wage, the price of intermediate good $i$, the price of the non-renewable resource, and the interest rate on a perfect financial market.

\subsubsection{Household}

The representative household maximizes (10) subject to its budget constraint $\dot{b}_{t}=r_{t} b_{t}+w_{t}+$ $\pi_{t}-C_{t}+T_{t}$, where $b_{t}$ is its total wealth, $\pi_{t}$ represents total profits - including the resource rent $p_{R t} R_{t}$ - in the economy and $T_{t}$ is a lump-sum subsidy (or tax). We then get the following

\footnotetext{
${ }^{15}$ We thank an anonymous referee for suggesting this tool.
} 
standard Ramsey-Keynes condition:

$$
\frac{\dot{C}_{t}}{C_{t}}=r_{t}-\rho
$$

\subsubsection{Non-renewable resource sector}

On the competitive natural resource market, the maximization of the profit function

$\int_{t}^{+\infty} p_{R s} R_{s} e^{-\int_{t}^{s} r_{u} d u} d s$, subject to $\dot{S}_{s}=-R_{s}, S_{s} \geq 0, R_{s} \geq 0, s \geq t$, yields the standard equilibrium "Hotelling rule":

$$
\frac{\dot{p}_{R t}}{p_{R t}}=r_{t}
$$

As usual, the transversality condition is $\lim _{t \rightarrow+\infty} S_{t}=0$.

\subsubsection{Final sector}

The final sector maximizes the following profit function:

$$
\begin{aligned}
\pi_{Y t}= & \left(\int_{0}^{A_{t}} x_{i t}^{\alpha} d i\right) L_{Y t}^{\beta} R_{t}^{\gamma}-\int_{0}^{A_{t}} p_{i t}(1-s) x_{i t} d i-w_{t} L_{Y t}-w_{t}(1-\varphi) L_{Q t}-p_{R t} R_{t} \\
& -\tau_{t} h\left(R_{t}-h^{\eta-1} R_{t}^{\eta} L_{Q t}^{1-\eta}\right)+\lambda_{t}\left(h R_{t}\right)^{\eta} L_{Q t}^{1-\eta}
\end{aligned}
$$

$s$ and $\varphi$ are constant rates of subsidy to the use of intermediate goods and labor in CCS activity, respectively. $\tau_{t}$ is a unit tax on polluting emissions $P_{t}$ (i.e., $\left.h R_{t}-\left(h R_{t}\right)^{\eta} L_{Q t}^{1-\eta}\right)$ and $\lambda_{t}$ is a subsidy to sequestered carbon $Q_{t}$. The first-order conditions of this program are:

$$
\begin{gathered}
\frac{\partial \pi_{Y t}}{\partial x_{i t}}=\alpha x_{i t}^{\alpha-1} L_{Y t}^{\beta} R_{t}^{\gamma}-p_{i t}(1-s)=0, \text { for all } i \\
\frac{\partial \pi_{Y t}}{\partial L_{Y t}}=\beta Y_{t} / L_{Y t}-w_{t}=0, \\
\frac{\partial \pi_{Y t}}{\partial R_{t}}=\gamma Y_{t} / R_{t}-p_{R t}-\tau_{t} h\left(1-\eta h^{\eta-1} R_{t}^{\eta-1} L_{Q t}^{1-\eta}\right)+\lambda_{t} \eta h^{\eta} R_{t}^{\eta-1} L_{Q t}^{1-\eta}=0, \\
\text { and } \frac{\partial \pi_{Y t}}{\partial L_{Q t}}=-(1-\varphi) w_{t}+\left(\tau_{t}+\lambda_{t}\right)(1-\eta) h^{\eta} R_{t}^{\eta} L_{Q t}^{-\eta}=0 .
\end{gathered}
$$

This last condition highlights the fact that the carbon tax $\tau$ and the subsidy to sequestered carbon $\lambda$ have similar effects on the effort put into the CCS activity. We develop this point later in Section 4.2.

In this study, it is useful to identify the "total" price paid by the final sector for the resource. We denote this by $\tilde{p}_{R}$. Profit function (17) shows that it is composed of three elements: the price paid to resource owners $\left(p_{R t}\right)$, the tax paid on carbon emissions $\left(\tau_{t} h\left(1-\left(L_{Q t} / h R_{t}\right)^{1-\eta}\right)\right.$ 
and the subsidy to sequestered carbon $\left(\lambda_{t} h\left(L_{Q t} / h R_{t}\right)^{1-\eta}\right)$. Following equation (17), we have

$$
\tilde{p}_{R t}=p_{R t}\left[1+\frac{\tau_{t} h}{p_{R t}}-\frac{\left(\tau_{t}+\lambda_{t}\right) h}{p_{R t}}\left(\frac{L_{Q t}}{h R_{t}}\right)^{1-\eta}\right] \equiv p_{R t} M_{t} .
$$

\subsubsection{Intermediate and research sectors}

Innovations are protected by infinitely lived patents. This gives rise to a monopoly position in the intermediate sector. The profit function of the $i^{t h}$ monopolist is $\pi_{i}^{m}=\left(p_{i}-1\right) x_{i}\left(p_{i}\right)$, where $x_{i}\left(p_{i}\right)$ is the demand for intermediate good $i$ by the final sector (see (18)). Hence, the price chosen by the monopolist is

$$
p_{i t} \equiv p=1 / \alpha, \text { for all } i \text {. }
$$

As a result, quantities and profits are symmetric. We get

$$
x_{i t} \equiv x_{t}=\left(\frac{\alpha^{2} L_{Y t}^{\beta} R_{t}^{\gamma}}{1-s}\right)^{1 /(1-\alpha)}
$$

and

$$
\pi_{i t}^{m} \equiv \pi_{t}^{m}=\frac{1-\alpha}{\alpha} x_{t}
$$

The market value of a patent is $V_{t}=\int_{t}^{+\infty}\left(\pi_{s}^{m}+\sigma_{s}\right) e^{-\int_{t}^{s} r_{u} d u} d s$, where $\sigma_{s}$ is a subsidy to research aimed at correcting the standard distortion caused by the intertemporal spillovers ${ }^{16}$. Differentiating this equation with respect to time gives

$$
r_{t}=\frac{\dot{V}_{t}}{V_{t}}+\frac{\pi_{t}^{m}+\sigma_{t}}{V_{t}}
$$

which states that bonds and patents have the same rate of return in equilibrium.

The profit function of the research sector is $\pi_{t}^{R D}=V_{t} \delta A_{t} L_{A t}-w_{t} L_{A t}$. Free-entry in this sector leads to the standard zero-profit condition:

$$
V_{t}=\frac{w_{t}}{\delta A_{t}}
$$

\subsubsection{Government}

The government's budget constraint comprises: the carbon tax $\left(\tau_{t} Q_{t}=\tau_{t}\left[h R_{t}-\left(h R_{t}\right)^{\eta} L_{Q t}^{1-\eta}\right]\right)$, the subsidy to the use of intermediate goods $\left(\int_{0}^{A_{t}} s p_{i t} x_{i t} d i=A_{t} s x_{t} / \alpha\right)$, the subsidy to re-

\footnotetext{
${ }^{16}$ Note that Barro and Sala-i-Martin (2003), for instance, consider a direct subsidy to labor in research; our assumption alleviates computational complexity in the present context of polluting non-renewable resources and abatement.
} 
search $\left(\sigma_{t}\right)$, the subsidy to labor in $\operatorname{CCS}\left(\varphi w_{t} L_{Q t}\right)$, the subsidy to sequestered carbon $\left(\lambda_{t} Q_{t}=\right.$ $\left.\lambda_{t}\left(h R_{t}\right)^{\eta} L_{Q t}^{1-\eta}\right)$ and the lump-sum subsidy (or tax) $T_{t}$ (see Section 3.1.1). Assuming that it is balanced at each date $t$, it can be written: $\tau_{t}\left[h R_{t}-\left(h R_{t}\right)^{\eta} L_{Q t}^{1-\eta}\right]-A_{t} s x_{t} / \alpha-\sigma_{t}-\varphi w_{t} L_{Q t}-$ $\lambda_{t}\left(h R_{t}\right)^{\eta} L_{Q t}^{1-\eta}-T_{t}=0$ for all $t$.

\subsection{Equilibrium}

The preceding first-order conditions enable us to determine the equilibrium in a decentralized economy, that is, the set of quantities, prices and growth rates at each date expressed as functions of the economic policy tools $(s, \sigma, \tau, \varphi$ and $\lambda)$. Like the planned economy, a decentralized economy is always in transition. We fully characterize the decentralized economy in Appendix 3 , where we provide all equilibrium levels and growth rates. In this section, we focus on the variables that are relevant to our analysis.

As we mentioned above, the three basic distortions concern research and polluting emissions. It should be recalled that, in the present model, there is no directed technical change ${ }^{17}$, in particular in the abatement technology. We do not study the links between the climate policy and research subsidies - for such analysis in a partial equilibrium framework, see for instance Goulder and Mathai (2000) or Gerlagh et al. (2008). Thus, in order to focus on climate policy, we assume here that research is optimally funded. In other words, both subsidies, $s$ and $\sigma$, are set at their first-best levels, that is $s=1-\alpha$, and $\sigma_{t}=V_{t} g_{A t}$ (for proof, see Appendix 3, Section i).

\subsubsection{Equilibrium with no climate policy}

We first consider the case in which no climate policy is implemented: $\tau_{t}=\lambda_{t}=0$ at each date. The economy immediately jumps to its steady-state, where the amount of labor devoted to CCS is nil (see equation (28)): $L_{Q t}=0$, which means that no carbon is abated $\left(Q_{t}=0\right)$. This, in turn, implies that the total potential emission is released into the atmosphere, i.e. $P_{t}=h R_{t}$. Moreover, since labor used in the production of the final good $\left(L_{Y}\right)$ is constant, labor devoted to the research sector $\left(L_{A}=1-L_{Y}\right)$ is also constant ${ }^{18}$. The flow of extraction at date $\mathrm{t}$ is $R_{t}=\rho S_{0} e^{-\rho t}$. This implies $g_{R}=-\rho$ for all $t$. Finally, the growth rate of output, $g_{Y}$, is equal to $\delta-\rho$, as in standard endogenous growth models with non-polluting non-renewable resources. This steady-state is

\footnotetext{
${ }^{17}$ For an endogenous growth model with a stock of pollution and directed technical change, see for instance Grimaud and Rouge (2008) or Acemoglu et al. (2012).

${ }^{18}$ This property stems from an arbitrage condition in the allocation of labor between production and research activities. A similar trade-off occurs at the social optimum; we give a more detailed analysis in Appendix 1 (Section i).
} 
obviously identical to the first-best steady-state when environmental preferences are nil, that is, when $\omega=0$ (see Section 2.2.1).

\subsubsection{Equilibrium with climate policies}

We now consider the equilibrium in presence of the climate policy tools. For obvious reasons, it is impossible to study all types of carbon tax and subsidy profiles. We therefore limit our analysis to specific types. We show in the next section (Section 4.1) that the first-best carbon tax is a linear function of $Y$. Moreover, studying the class of economic policy tools that are growing at the same rate as output enables us to fully characterize the equilibrium, and in particular to obtain a closed-form solution for resource extraction. We thus focus on a climate policy such that $\tau_{t}=a_{1} Y_{t}$ and $\lambda_{t}=a_{2} Y_{t}$, where $a_{1}$ and $a_{2}$ are positive constants.

The main findings are the following. Labor in final good production, $L_{Y}$, is constant over time, and $L_{Q t}$, the effort in CCS, is given by

$$
L_{Q t}=\left[\frac{\left(\tau_{t}+\lambda_{t}\right) \rho(1-\eta)}{(1-\varphi) \delta(1-\alpha) Y_{t}}\right]^{1 / \eta} h R_{t}
$$

Here, we assume $0 \leq\left(\tau_{t}+\lambda_{t}\right) / Y_{t} \leq(1-\varphi) \delta(1-\alpha) / \rho(1-\eta)$ in order to avoid the corner solution in which the whole carbon content of $R_{t}$ is abated at each time. The flow of resource extraction is given by

$$
R_{t}=\frac{\gamma}{\psi_{0} e^{\rho t}+G}
$$

where $\psi_{0}=G /\left(e^{\frac{G \rho S_{0}}{\gamma}}-1\right)$ and $G=\frac{h \tau_{t}}{Y_{t}}-\eta h\left(\frac{\rho(1-\eta)}{(1-\varphi) \delta(1-\alpha)}\right)^{\frac{1-\eta}{\eta}}\left(\frac{\tau_{t}+\lambda_{t}}{Y_{t}}\right)^{\frac{1}{\eta}}$ (see Appendix 3 (iii)). Since $\tau_{t} / Y_{t}$ and $\lambda_{t} / Y_{t}$ are constant, $G$ is constant. The growth rate of resource extraction is

$$
g_{R t}=\frac{-\rho}{1+\left(e^{\frac{G \rho S_{0}}{\gamma}}-1\right) e^{-\rho t}} .
$$

$g_{R t}$ is negative and asymptotically converges toward its long-run level $-\rho$. Along the transition, it can be seen that if $G>0$, then $g_{R t}$ is higher than its asymptotic value, while if $G<0$, it is lower. The value of $G$ depends on the relative values of $\tau_{t}$ and $\lambda_{t}$.

Since the effort in CCS $\left(L_{Q t}\right)$, abated carbon $\left(Q_{t}\right)$ and pollution $\left(P_{t}\right)$ are all linear functions of $R_{t}$, they also decrease over time ${ }^{19}$. Since $L_{Q t}$ decreases over time, labor devoted to research,

\footnotetext{
${ }^{19}$ If we consider technical progress in the CCS function, for instance $Q_{t}=\left(h R_{t}\right)^{\eta}\left(A_{Q t} L_{Q t}\right)^{1-\eta}$, where $A_{Q t}$ grows over time at exogenous rate, then $(28)$ becomes $L_{Q t} / h R_{t}=\left[\tau_{t} \rho(1-\eta) /(1-\varphi) \delta(1-\alpha) Y_{t}\right]^{1 / \eta} A_{Q t}^{(1-\eta) / \eta}$. $L_{Q t} / h R_{t}$ and $Q_{t} / h R_{t}$ are then increasing functions of time, which is more consistent with Grimaud et al. (2011), for instance. In this case, even if $R_{t}$ decreases over time, $Q_{t}$ can increase over some intervals of time.
} 
$L_{A t}$, increases over time and converges to the constant level $1-L_{Y}=1-\beta \rho / \delta(1-\alpha)$ as time tends to infinity. Note that the levels of CCS effort, sequestration, pollution and extraction depend on economic policy tools - the effects of economic policies are analyzed in the following section.

The level and the growth rate of output are given by

$$
\begin{gathered}
Y_{t}=\alpha^{\alpha /(1-\alpha)} A_{t} L_{Y}^{\beta /(1-\alpha)} R_{t}^{\gamma /(1-\alpha)}, \\
\text { and } g_{Y t}=g_{A t}+(\gamma /(1-\alpha)) g_{R t} .
\end{gathered}
$$

Since $g_{A t}=\delta L_{A t}$ (see equation (2)), $g_{A t}$ increases over time and tends to $\delta-\beta \rho /(1-\alpha)$. Simultaneously, $g_{R t}$ tends to its limit $-\rho$ (see equation (30)). Thus, in the long run, $g_{Y t}$ tends to $\delta-\rho$, which we can consider positive. This is a fairly standard expression of long-run output growth in a model with non-renewable resources - see for instance Stiglitz (1974), in the context of an exogenous growth model without pollution. Along the transition path, however, $g_{A t}$ is lower than its long-run level and $g_{R t}$ can be lower or higher according to the relative values of the carbon tax and the subsidy to sequestered carbon - see comments below equation (30). Thus, over some intervals of time, output growth can be positive or negative. We provide further elements on the impact of the economic policy tools on output growth in the next section.

\section{Economic policies}

\subsection{First best climate policy}

We now characterize the first-best policy. It should be remembered that there are three basic market failures in this economy. Since we have set the research subsidies at their optimal levels, only the environmental distortion remains. Hence, in order to implement the first-best, it is only necessary to set the carbon tax at its Pigovian level. Obviously, there is no need here for the CCS tools, that is, the subsidies to sequestered carbon and to labor in CCS. Thus we set $\lambda=\varphi=0$ in this section.

Proposition 1 At each date $t, \tau_{t}^{o}=\frac{\omega(1-\alpha)}{\rho+\theta} Y_{t}$ is the level of carbon tax that implements the socially optimal path. This tax is unique, and it generally increases over time.

Proof. Comparing the socially optimal levels of the variables to their levels in the decentralized equilibrium, for instance $L_{Q t}^{o} / h R_{t}^{o}(11)$ and $L_{Q t} / h R_{t}(28)$, yields $\tau_{t}^{o}$. One can then easily check that all the other variables in the decentralized economy are at their socially optimal levels. 


\section{Economic interpretation of the first-best carbon tax}

It can be shown that, if we use the non-specified expression of the utility function, $U\left(C_{t}, Z_{t}\right)$, the optimal tax is equal to $\frac{-1}{U_{C}} \int_{t}^{+\infty} U_{Z} e^{-(\rho+\theta)(s-t)} d s>0$, since $U_{Z}<0$. Thus the optimal tax is the product of two terms. The first, $1 / U_{C}$, is the amount of consumption good that compensates for a marginal change in utility. The second, $-\int_{t}^{+\infty} U_{Z} e^{-(\rho+\theta)(s-t)} d s$, is the expression of the optimal tax in terms of utility, that is, the sum of discounted social costs of one unit of carbon emitted at date $t$, for all (present and future) times. Hence, $\tau_{t}^{o}$ is the sum of discounted social costs of one unit of carbon measured in terms of final good.

With the specified functional form (10), the first-best tax level is linear in the output level. Indeed, since utility is separable and linear in the damage, the term $-\int_{t}^{+\infty} U_{Z} e^{-(\rho+\theta)(s-t)} d s$ is constant and equal to $\omega /(\rho+\theta)$. Moreover, since the utility of consumption is logarithmic, $1 / U_{C}$ is equal to $C_{t}=(1-\alpha) Y_{t}$. Thus we have $\tau_{t}^{o}=\frac{\omega(1-\alpha)}{\rho+\theta} Y_{t}$. If the environmental damage was introduced in the production function as a multiplicative argument with an exponential form as in Golosov et al. (2011) or Gerlagh and Liski (2012), the first-best tax would have the same form ${ }^{20}$.

Note that the tax level matters here. Indeed, when abatement technology is available, the social planner has to give firms the right incentive in terms of social costs of pollution, so as to induce the optimal effort in abatement. Thus, the optimal tax has to be equal to $\partial Y_{t} /$ $\partial Q_{t} \equiv\left(\partial Y_{t} / \partial L_{Y t}\right) /\left(\partial Q_{t} / \partial L_{Q t}\right)$, which is the cost of sequestering one unit of carbon ${ }^{21}$ - indeed, increasing CCS leads to a decrease in output through a labor transfer from the final good sector to CCS. Since $\partial Y_{t} / \partial L_{Y t}=\beta Y_{t} / L_{Y t}$ and $\partial Q_{t} / \partial L_{Q t}=(1-\eta) Q_{t} / L_{Q t}$, using the optimal values given in Appendix 1 (Section vii), we get $\tau_{t}^{o}$ as expressed in the proposition. This sharply contrasts with the standard result in the literature without abatement which states that the tax level generally does not matter (see Dasgupta and Heal, 1979; Sinclair, 1992; Groth and Schou, 2007; or Grimaud and Rouge, 2008 for instance). In this context, there are an infinity of optimal taxes which have the same dynamics, but differ in their levels. Here, in a model featuring CCS, we have shown that the first-best tax is unique.

\footnotetext{
${ }^{20}$ Indeed, if the environmental damage is entered as an argument in the production function $(Y=F(Z, \ldots))$, the general expression of the first-best tax is $\frac{-1}{U_{C}} \int_{t}^{+\infty}\left(U_{C} F_{Z}+U_{Z}\right) e^{-(\rho+\theta)(s-t)} d s$. Suppose that $Z$ appears in the production function as a multiplicative argument with an exponential form: $Y_{t}=\left(\int_{0}^{A_{t}} x_{i t}^{\alpha} d i\right) L_{Y t}^{\beta} R_{t}^{\gamma} e^{-\varpi Z t}$, $\varpi>0$. The tax expressed in terms of utility is then $(\omega+\varpi) /(\rho+\theta)$. Expressed in terms of final good, the first-best tax is thus equal to $(\omega+\varpi)(1-\alpha) Y_{t} /(\rho+\theta)$. It depends on the impact of emissions on both utility $(\omega)$ and output production $(\varpi)$.

${ }^{21}$ Goulder and Mathai (2000) provide a similar expression in a partial equilibrium context with exogenous baseline emissions, that is, exogenous total carbon content in our framework (see equation (11) in their paper).
} 
Finally, $\tau_{t}^{o}=\left(-\zeta_{t}\right) e^{\rho t}(1-\alpha) Y_{t}$, where $\zeta_{t}$ is the co-state variable associated with the stock of carbon $Z_{t}$ in the social planner program (see Appendix 1, equation (42)). This socially optimal tax can be linked to the ones obtained in partial equilibrium frameworks: see for instance Hoel and Kverndokk (1996, equation (17)), Goulder and Mathai (2000, equation (13)) or Gerlagh et al. (2008, equation (18)). However, in our context, this tax exhibits specific properties, which we comment on below.

\section{Main properties of the first-best carbon tax}

For obvious reasons, the first-best tax is increasing in environmental preferences $\omega$ and decreasing in the psychological discount rate $\rho$ and the rate of natural $\mathrm{CO}_{2}$ decay $\theta$.

Moreover, since the tax is proportional to output, its growth rate is equal to the growth rate of output - which is generally positive. The economic intuition behind this property is the following. If $g_{Y t}>0$, the marginal utility of consumption decreases over time. Thus, the amount of final good that compensates the household for the emission of one unit of carbon increases over time. Observe that the Pigovian tax is increasing even if utility is a linear function of $Z_{t}$. A convex functional form would probably reinforce this result - see for instance the discussion on this issue in Goulder and Mathai (2000, p.34). This confirms what is obtained by Grimaud et al. (2011) in a calibrated model, in the absence of a carbon ceiling. Finally, since $g_{\tau}^{o}=g_{Y}^{o}$, the Ramsey-Keynes condition (15) implies $g_{\tau}^{o}=r-\rho<r$; in other words, this policy will postpone resource extraction - see Dasgupta et al. (1981) on this issue.

Remark: Ex-post interpretation of the increasing unit carbon tax.

In many growth models with climate change (see for instance Sinclair, 1992, Groth and Schou, 2007, or Grimaud and Rouge, 2008), the socially optimal policy instrument consists of a decreasing ad-valorem tax on resource use - which is equivalent to a tax on carbon emissions if there is no abatement. Here we have shown that the optimal tool is an increasing unit tax on carbon emissions. Both results can be linked. Indeed, the optimal carbon tax, which leads the decentralized economy to postpone resource extraction, can be interpreted ex-post as a decreasing ad valorem tax on the resource. When the optimal tax is implemented, the total (i.e., including the price of the resource and the carbon tax) unit price paid by users for the resource increases less rapidly than the unit price perceived by owners of the resource -whose growth rate is equal to the interest rate. That is why extraction is postponed. Ex-post, this has the same effect as a decreasing ad valorem tax. Indeed, we have seen that the total price paid by firms for the resource is $\tilde{p}_{R t}$ (see (22)). Using (28) and $\tau_{t}^{o}=\omega(1-\alpha) Y_{t} /(\rho+\theta)$ (see Proposition 
1), $\tilde{p}_{R t}$ is equal to $p_{R t}\left[1+\left(1-\left(\frac{\omega \rho(1-\eta)}{\delta(\rho+\theta)}\right)^{(1-\eta) / \eta}\right) \frac{\omega(1-\alpha) h Y_{t}}{(\rho+\theta) p_{R t}}\right]$ at the first-best. Thus, $\tilde{p}_{R t}$ can be written as $p_{R t}\left(1+\xi_{t}\right)$, where $\xi_{t}$ can be interpreted as an ad valorem tax on the resource. Since $g_{Y t}=r_{t}-\rho$ and $g_{p_{R t}}=r_{t}$, the ratio $Y_{t} / p_{R t}$ decreases over time and so does the ad valorem $\operatorname{tax}$.

\subsection{Impact of second-best economic policies}

We suppose here that the Pigovian level of the carbon tax - stated in Proposition 1- cannot be achieved by the policy maker, and that it can only be lower than this level at each date $t$. As mentioned above, many reasons could explain this situation, such as a lack of international political consensus. In this case, additional policies could prove useful. We thus study the impact of second-best policies: a carbon tax $\tau_{t}$ inferior to $\tau_{t}^{o}{ }^{22}$, the subsidy to sequestered carbon $\lambda_{t}$ and the subsidy to labor in CCS $\varphi$. We first analyze how CCS activity is affected. Here, the key transmission channel of the policies is the trade-off between labor in R\&D and CCS. Second, the time profile of resource use is modified. The transmission channel is the impact of these policies on the dynamics of the total price paid by the final sector for the resource. We then study the impact on carbon emissions, which obviously depends on the impact on CCS as well as the impact on resource use. Finally, we show how the changes in resource extraction and knowledge accumulation also affect the levels and growth rates of output and consumption.

When they are not necessary, we drop time subscripts for notational convenience.

\subsubsection{Carbon tax}

We first consider the impact of the carbon tax $\tau$. We have shown in Section 4.1 that the first-best level of the carbon tax is strictly positive; we thus study here the impact of setting a positive carbon tax in an economy where there is none, or, equivalently, of increasing the tax level if one is already in place. We implicitly assume that, in either case, the tax level is below its first-best level. This means that the studied policy is always welfare-improving - even if, as we shall see, it can reduce output and consumption in the short run. As mentioned above, we focus on a policy such that the ratio $\tau / Y$ is constant. The main relevant effects of this policy on the equilibrium trajectories of the economy are presented in the following proposition.

\footnotetext{
${ }^{22}$ We include the carbon tax in the second-best tools when it is below its first-best level in order to simplify our presentation.
} 
Proposition 2 An increase in $\tau / Y$ has the following impact on the economy.

(i) The rate of CCS activity rises: for any extraction flow $(R)$, the effort in $C C S\left(L_{Q}\right)$ and the flow of sequestered carbon $(Q)$ increase.

(ii) Resource extraction is postponed: $R$ decreases in the short term and increases in the long term.

(iii) The rate of carbon emissions decreases: for any level of $R$, the flow of carbon emissions $(P)$ decreases. Hence $P$ unambiguously decreases in the short term.

(iv) The tax reduces the short-term levels of output $(Y)$ and consumption $(C)$ and it generally fosters economic growth. However, if the weight of the CCS sector in the whole economy is high, the tax can reduce growth.

Proof. See Appendix 3 (Section v).

The result presented in item (i) is due to the fact that the carbon tax makes CCS activity more profitable. Here, the key transmission channel is the trade-off between labor in research and CCS: the policy leads to an additional effort in CCS which is drawn from the R\&D activity. This trade-off has been analyzed in the comments below equation (11): the effects of the carbon tax are identical to an increase in $\omega$ or $\rho$. Formally, the amount of labor by unit of carbon content, $L_{Q} / h R$ (see equation (28)), increases - remember that the carbon content of a given flow of resource use, $h R$, is the total potential carbon emissions associated with the extracted resource, $R$. Therefore, the instantaneous rate of CCS, that is, the amount of sequestered carbon relative to the total carbon content of the flow of extracted resource, $Q / h R$, also increases.

The carbon tax modifies the dynamics of resource extraction. Resource use is monotonous and decreasing; since $\partial g_{R t} / \partial\left(\tau_{t} / Y_{t}\right)>0$ for all $t$, we get the result presented in item (ii). The key transmission channel is the resource price. To understand it, consider the total price paid by the final sector for the resource, $\tilde{p}_{R}$ (see equations (22) and (28)). The growth rate of $\tilde{p}_{R}$ is equal to $g_{p_{R}}+g_{M}$. According to the sign of $g_{M}$, the total price of the resource grows more or less rapidly than $p_{R}$. Equation (22) shows that the ratio $\tau / p_{R}$ plays a key role. It can be rewritten as $(\tau / Y) .\left(Y / p_{R}\right)$. Since $\tau / Y$ is constant, and $g_{Y / p_{R}}=-\rho$ (see equations (15) and (16)), we have $g_{\tau / p_{R}}=g_{Y}-g_{p_{R}}=-\rho$. Similarly, $g_{\lambda / p_{R}}=-\rho$. Hence, we obtain $g_{M}=\rho(1-M) / M$. In order to isolate the effects of the carbon tax on the dynamics of the total price of the resource, we assume here that $\lambda_{t}=0$ for all $t$. In this case, $M=1+\frac{\tau h}{p_{R}}\left[1-\left(\frac{\tau \rho(1-\eta)}{Y(1-\varphi) \delta(1-\alpha)}\right)^{(1-\eta) / \eta}\right]$. If $\tau / Y>0$, using the fact that $0 \leq \tau / Y \leq(1-\varphi) \delta(1-\alpha) / \rho(1-\eta)$ - see Section 3.2.2 -, it is clear that $M>1$. Thus, $g_{M}$ is negative. In other words, when $\tau / Y>0$, we have $\tilde{p}_{R t}>p_{R t}$ with 
$g_{\tilde{p}_{R t}}<r_{t}$, for all $t$. So, when the policy maker implements a climate policy, the total price of the resource $\tilde{p}_{R}$ is higher but it grows less rapidly. Hence, the instantaneous flows of resource use are reallocated over time: less resource is extracted today, and more tomorrow. In other words, resource extraction is postponed.

Item (iii) presents the impact of the tax on carbon emissions. Since $Q / h R$ increases (item (i)), effective pollution by unit of carbon content, i.e. the quantity of carbon actually emitted relative to the carbon that would be emitted without the CCS option, $P / h R$, decreases. Since the tax has the effect of reducing resource extraction in the short term, effective carbon emissions unambiguously also decrease in the short term.

This climate policy also modifies the level and growth of output (item (iv) in Proposition 2). Since consumption is a linear function of output, as shown in Appendix 3 (Section i), the effects on output and consumption are identical. Output level is given by equation (31). In the short run, one can consider that the changes to the stock of knowledge, that is, the state variable $A$, are negligible compared with changes to the flow of resource use $R$. Hence, the postponement of resource extraction, which drives the economy to less resource use, negatively impacts output. In sum, the carbon tax reduces output and consumption in the early stages.

The impact on output growth is less straightforward. Equation (32) shows that two different effects drive this impact: the effect of the tax on knowledge growth $\left(g_{A}\right)$ and the effect of the tax on the growth rate of resource extraction $\left(g_{R}\right)$. In the absence of CCS technology, the effect on research is nil, since the allocation of labor between production and research is unchanged over time (see equation (43) in Appendix 3). In this case, since the climate policy postpones resource extraction, i.e. $g_{R}$ increases, it unambiguously promotes output growth ${ }^{23}$. If a carbon abatement technology is available however, the effect on the research effort - and hence on the growth of knowledge - can play a key role since there is now a third competing use for labor. Using equations (2) and (9), we can see that the sign of $\partial L_{A} / \partial(\tau / Y)$ is opposite to the sign of $\partial L_{Q} / \partial(\tau / Y)$ - since, here also, $L_{Y}$ is constant. We have shown that $L_{Q}=$ $[\tau \rho(1-\eta) / \delta(1-\alpha) Y]^{1 / \eta} h R$ (equation (28)). An increase in $\tau / Y$ has a positive impact on the term between brackets: for a given level of extraction, the tax increases the price of carbon used in the CCS process, which prompts a rise in $L_{Q}$. However, as we have already seen, it also has a negative impact on $R$ in the short run and a positive impact in the long run. Hence, the total

\footnotetext{
${ }^{23}$ This contradicts the general finding of models in which pollution is a by-product of production or capital, and does not result from the use of non-renewable resources. Most of these models, when no specific assumptions on, say, returns to scale on the abatement technology or the external effects of environmental quality on productivity are made, show that there is a trade-off between environmental quality and economic growth (Gradus and Smulders, 1993, or Grimaud, 1999). For a survey of this question, see for instance Ricci (2007).
} 
effect of the tax on $L_{Q}$ is positive in the long run but ambiguous in the short run. The effect of the carbon tax on $L_{A}$ and thus on $g_{A}$ being opposite to the effect on $L_{Q}$, one can see that the impact of the tax on the growth of knowledge is negative in the long run but ambiguous in the short run. Since this tax has a positive impact on $g_{R}$, the overall effect on output growth is ambiguous in the short term and the long term.

We have seen that the carbon tax reallocates labor from research to CCS activities. Assume that the weight of the CCS sector in the economy is low; in other words, the amount of reallocated labor is negligible. This means that whatever the impact of the tax on knowledge growth, it does not surpass the positive impact on the growth of resource use. In this case, the tax fosters growth. If the weight of the CCS sector is high, however, the carbon tax can reduce output growth.

\subsubsection{Subsidy to sequestered carbon}

Here we consider the effects of the subsidy to sequestered carbon $\lambda$. As previously mentioned, we restrict our analysis to subsidies that grow at the same rate as output, that is, $\lambda / Y$ is constant. We study the impact of setting a positive subsidy in an economy where there is none, or, equivalently, of increasing the level of the subsidy if it is already implemented. The effects of such policies on the equilibrium trajectories of the economy are described in the following proposition.

Proposition 3 An increase in $\lambda / Y$ has the following impact on the economy.

(i) Like the carbon tax, the subsidy increases the rate of CCS activity - see item (i) in Proposition 2.

(ii) Contrary to the tax, the subsidy accelerates resource extraction: $R$ increases in the short term and decreases in the long term.

(iii) The rate of carbon emissions decreases: for any level of $R$, the flow of carbon emissions $(P)$ decreases. Hence the subsidy can decrease or increase short-term emissions.

(iv) Contrary to the tax, the subsidy increases the short-term levels of output $(Y)$ and consumption $(C)$ and it generally reduces economic growth. However, if the weight of the CCS sector in the whole economy is high, the subsidy can foster long-term growth .

Proof. See Appendix 3 (Section vi).

Like the carbon tax, the subsidy to sequestered carbon makes CCS activity more profitable. Its impact on $L_{Q} / h R$, and thus $Q / h R$, is summarized in equation (28). Here, $\lambda$ and $\tau$ are 
perfect substitutes since they appear in a sum. Henceforth, their impacts are clearly identical item (i) in Proposition 2. Moreover, if $\tau<\tau^{o}$ - and, in particular, if $\tau=0$-, the policy maker can always set $\lambda=\tau^{o}-\tau$ and restore the socially optimal $L_{Q} / h R$ and $Q / h R$. Nonetheless, the levels of $L_{Q}$ and $Q$ will not be socially optimal since, as we show below, this level of subsidy does not entail socially optimal resource extraction.

The impact of the subsidy on resource extraction is opposite to the impact of the carbon tax. This means that $g_{R}$ decreases. The subsidy to sequestered carbon thus accelerates resource extraction. To understand this, we study how the resource price is affected by this policy. Remember that the total price paid for the resource by the final sector is given by (22) and (28). The case we consider here is symmetric to the case studied in Section 4.2.1, that is, in order to study the effects of the subsidy on the dynamics of this price, we assume that the carbon tax is nil: $\tau_{t}=0$ for all $t$. In this case, $M=1-\frac{\lambda h}{p_{R}}\left(\frac{\lambda \rho(1-\eta)}{Y(1-\varphi) \delta(1-\alpha)}\right)^{(1-\eta) / \eta}$. Here $M<1$, which means that $g_{M}>0$. In other words, the subsidy lowers the level of the price paid for the resource but makes it grow faster: $\tilde{p}_{R t}<p_{R t}$ and $g_{\tilde{p}_{R t}}>r_{t}$ for all $t$. This entails a reallocation of instantaneous resource uses over time so that more resource is extracted today and less tomorrow, i.e. resource extraction is accelerated: $g_{R}$ decreases - item (ii) in Proposition 3.

The impact of the subsidy on carbon emissions (item (iii) in Proposition 3) is more complex.

We have seen that, like the carbon tax, the subsidy increases $Q / h R$, which leads to a decrease in $P / h R$. However, the subsidy entails a higher resource use in the short run. The overall impact on short-term carbon emissions is thus ambiguous. This means that a type of green paradox can occur here. Indeed, following Sinn (2008) and subsequent contributions like Gerlagh (2011) and van der Ploeg and Withagen (2012), a (weak) green paradox occurs when climate policies induce a more rapid extraction of fossil fuels, thus increasing short-term emissions. Here, two opposite effects drive short-term effective emissions: more resource is extracted, and more carbon is sequestered. If the former effect surpasses the latter, then the subsidy to CCS yields higher carbon emissions in the short run.

We finally turn to the impact of this policy on output and consumption (item (iv) in Proposition 3). The effect on output level (31) in the short run is opposite to the effect of the tax: more resource is used in the early stages, which tends to increase output and consumption in the short run. The effect on economic growth is determined by the combination of the effect on the growth of resource use and the effect on the growth of knowledge. As demonstrated above, the 
subsidy entails a decrease in $g_{R}$. If this effect is strong, and thus exceeds any possible positive impact on research, output growth (32) decreases. We have shown in the preceding subsection that $g_{A}$ is a decreasing function of $L_{Q}$. The impact of the subsidy on $L_{Q}$ is deduced from equation (28). We can see that the increase in $\lambda / Y$ has a positive effect on the term between brackets. Moreover, we have stated that the effect on $R$ is positive in the short run and negative in the long run. Therefore, the impact of the subsidy on knowledge growth is negative in the short run and ambiguous in the long run. Hence, the overall effect of the subsidy to sequestered carbon on output growth is unambiguously negative in the short run and ambiguous in the long run.

Assume that the weight of the CCS sector in the whole economy is low; as mentioned in the previous subsection, this means that the amount of labor reallocated from R\&D to CCS is negligible. In such a case, the impact of the subsidy on the growth rate of resource use dominates, and the tax is unambiguously bad for growth. However, if the weight of the CCS sector is high, one can see that, unlike the carbon tax, the subsidy can foster long-run growth.

More generally, the advantage of this policy is twofold. First, for many reasons - in particular, political consensus issues -, the first-best level of the carbon tax is not likely to be reached. One may therefore suppose that a complementary tool, such as a subsidy to sequestered carbon, may help to increase welfare along the equilibrium trajectories of the economy. Second, we have seen that the impacts of both policies are sometimes opposed, in particular on production and consumption in the short run. Whereas the carbon tax entails a decrease in output, the subsidy fosters it. In other words, the latter tool helps to reduce the burden of climate policy in the earlier periods. One might then think that mixing both policies could favor public acceptance when the regulator has to implement her policy scheme.

Remark: We have seen that the carbon tax and the subsidy to sequestered carbon have opposite effects on the time profile of resource extraction: the tax postpones it while the subsidy accelerates it. When these two policies are applied simultaneously, the effect of the tax on extraction conflicts with that of the subsidy. However, we are able to characterize the overall effect on the growth rate of resource extraction of any couple $\left(\tau_{t} ; \lambda_{t}\right)$. Indeed, we have shown in the comments below equation (30) that $g_{R t}$ is higher (resp. lower) than $-\rho$, i.e. resource extraction is postponed (resp. accelerated), if $G>0$ (resp. $<0)$. This means that resource extraction is postponed (resp. accelerated) if and only if $\lambda_{t}$ is lower (resp. higher) than $\eta^{-\eta}$ $\left[\rho(1-\eta) / Y_{t}(1-\varphi) \delta(1-\alpha)\right]^{\eta-1} \tau_{t}^{\eta}-\tau_{t}$. 


\subsubsection{Subsidy to labor in CCS}

We finally consider the subsidy to labor in CCS, $\varphi$. The main effects of this tool are summarized in the following proposition.

Proposition 4 The subsidy to labor in CCS $\varphi$ has an impact on the economy only if it is implemented together with a complementary climate policy, that is, if $\tau>0$ and/or $\lambda>0$. In such a case, the effects of $\varphi$ are similar to the effects of the subsidy to sequestered carbon $\lambda$ (presented in Proposition 3).

Proof. All these results are found by differentiating equations (28)-(30), and (45), (46), (49) and (50) in Appendix 3 with respect to $\varphi$.

First, in the absence of the carbon tax $(\tau)$ and the subsidy to sequestered carbon $(\lambda)$, a subsidy to labor in CCS has no effect on the economy. This can be observed in equations (28) and (30). One can see that, if $\tau=\lambda=0$, then $L_{Q}=0$, that is, there is no CCS activity, and $g_{R}=-\rho$ since $G=0$. Indeed, carbon - sequestered or emitted - has no price, and thus CCS activity is not profitable.

When this policy is implemented together with a carbon tax and/or a subsidy to sequestered carbon, the subsidy to labor does have an impact. First, the profitability of CCS resulting from the implementation of the carbon tax and/or the subsidy to sequestered carbon is strengthened by the subsidy to labor. Thus $L_{Q} / h R$ and $Q / h R$ increase.

Second, the subsidy accelerates resource extraction. To understand this, we again need to analyze how this tool affects the dynamics of the total price paid by the resource user. By using equation (22), we get $\partial M / \partial \varphi<0$ and thus $\partial g_{M} / \partial \varphi>0$. The subsidy to labor therefore accelerates the growth of the total price of the resource, and consequently its extraction.

If $\tau_{t}>0$ and $\lambda_{t}=0$, we have seen in Section 4.2.1 that $\tilde{p}_{R}$ grows less fast than $p_{R}$. Hence the subsidy to labor in CCS goes against the effect of the carbon tax on resource extraction. If $\tau_{t}=0$ and $\lambda_{t}>0$, as stated in Section $4.2 .2, \tilde{p}_{R}$ grows faster than $p_{R}$; so $\varphi$ strengthens the effect of the subsidy to sequestered carbon. This obviously means that, like the subsidy to sequestered carbon, the subsidy to labor in CCS can yield a green paradox.

When $\tau_{t}>0$ and/or $\lambda_{t}>0$, the subsidy to labor $\varphi$ affects the levels and growth of output and consumption in the same way as $\lambda$, since their impact on knowledge accumulation and resource extraction are alike. For the same reasons, this policy can be seen as a good complement to a carbon tax since, while strengthening its impact on CCS activity, it can favor its social acceptance by alleviating its burden at the early stages. 


\section{Conclusion}

We have developed an endogenous growth model with climate change that features CCS technology. Such an abatement technology can be used to endogenize $\mathrm{CO}_{2}$ emissions for a given use of fossil fuel.

We have fully depicted the socially optimal outcome of this economy and we have shown that the greatest effort in CCS should be undertaken today. Moreover, the availability of CCS technology can produce a rise in $\mathrm{CO}_{2}$ emissions in the short run since it speeds up the pace of resource extraction, which can offset the CCS activity. We have computed the first-best carbon tax, which is unique and generally increasing over time.

We have fully characterized the decentralized economy's trajectories and, when the Pigovian carbon tax cannot be implemented, we have studied three types of second-best economic policies. The first one is a standard unit tax on carbon emissions. The second and the third are subsidies to sequestered carbon and the effort in CCS, respectively. The latter has an impact on the economy only if it is implemented together with at least one of the two other climate policies (the carbon tax or the subsidy to sequestered carbon). If so, the two subsidies have similar impacts.

The three tools foster CCS activity. However, their impacts on resource extraction are opposite: the carbon tax postpones resource extraction whereas the two subsidies accelerate it. Therefore, while the tax unambiguoulsy decreases short-term carbon emissions, the two subsidies can yield a green paradox in the form of a rise in short-term emissions.

The carbon tax has a negative impact on the levels of output and consumption in the short term contrary to the subsidies. In this sense, the subsidies can favor the public acceptance of a carbon tax. The effects on growth are more complex. The carbon tax generally fosters growth whereas the subsidies reduce it. However, when the weight of the CCS sector in the economy is high, that is, if the rise in CCS drains an important amount of labor from research activities, the carbon tax can reduce output growth while the two subsidies can foster it in the long term.

It remains necessary to move away from a carbon economy by switching to renewable or non-fossil fuel based energy sources (Gerlagh, 2006). In order to keep the model tractable, the availability of a clean and renewable energy source has not been introduced. This so-called backstop would not drastically alter the qualitative properties of our results. Nevertheless, it would be interesting to study the impact of the CCS option on the adoption timing of these alternative sources of energy. We can infer that the possibility of sequestering carbon emissions would delay the introduction of renewable energy. 


\section{Appendix}

\section{Appendix 1: Welfare}

We drop time subscripts for notational convenience. The social planner maximizes $U=\int_{0}^{+\infty}(\ln C-$ $\omega Z) e^{-\rho t} d t$ subject to (1)-(9). We assume that $[\rho \omega(1-\eta) / \delta(\rho+\theta)]^{1 / \eta}<1$ (see equation (11)) in order to avoid a corner solution in which carbon emissions are fully abated, i.e. $L_{Q}=h R$. Thus, it is unnecessary to incorporate a Kuhn-Tucker condition for $L_{Q} \leq h R$. The Hamiltonian of the program is

$$
\begin{aligned}
H= & (\ln C-\omega Z) e^{-\rho t}+\mu \delta A\left(1-L_{Y}-L_{Q}\right)-\nu R+\zeta\left[h\left(R-h^{\eta-1} R^{\eta} L_{Q}^{1-\eta}\right)+\theta\left(Z_{0}-Z\right)\right] \\
+\chi & {\left[\left(\int_{0}^{A} x_{i}^{\alpha} d i\right) L_{Y}^{\beta} R^{\gamma}-C-\int_{0}^{A} x_{i} d i\right] }
\end{aligned}
$$

where $\mu, \nu, \zeta$ and $\chi$ are the co-state variables. The first order conditions $\partial H / \partial C=0$ and $\partial H / \partial x_{i}=0$ yield

$$
e^{-\rho t} / C-\chi=0
$$

$$
\text { and } \alpha x_{i}^{\alpha-1} L_{Y}^{\beta} R^{\gamma}-1=0 \text {, for all } i \text {. }
$$

Note that this implies $x_{i}=x$, for all $i . \partial H / \partial L_{Y}=0, \partial H / \partial L_{Q}=0$ and $\partial H / \partial R=0$ yield

$$
\begin{gathered}
-\mu \delta A+\chi \beta Y / L_{Y}=0, \\
-\mu \delta A-\zeta h^{\eta}(1-\eta) R^{\eta} L_{Q}^{-\eta}=0, \\
\text { and } \zeta h\left(1-\eta h^{\eta-1} R^{\eta-1} L_{Q}^{1-\eta}\right)+\chi \gamma Y / R-\nu=0 .
\end{gathered}
$$

Moreover, $\partial H / \partial A=-\dot{\mu}, \partial H / \partial S=-\dot{\nu}$, and $\partial H / \partial Z=-\dot{\zeta}$ yield

$$
\begin{gathered}
-\dot{\mu}=\mu \delta L_{A}+\chi\left(x^{\alpha} L_{Y}^{\beta} R^{\gamma}-x\right), \\
-\dot{\nu}=0 \\
\text { and }-\dot{\zeta}=-\omega e^{-\rho t}-\zeta \theta
\end{gathered}
$$

i) Computation of $L_{Y}$.

(34) can be rewritten as $Y=A x / \alpha$. Since $Y=C+A x$, one gets $C=(1-\alpha) Y$. 
Dividing both hand sides of (38) by $\mu$ gives $-g_{\mu}=\delta L_{A}+\left(x^{\alpha} L_{Y}^{\beta} R^{\gamma}-x\right) \chi / \mu$. The term between brackets can be rewritten as $Y / A-\alpha Y / A$, which is equal to $(1-\alpha) Y / A$. Moreover, from (35), we have $\chi / \mu=\delta A L_{Y} / \beta Y$ and $g_{\mu}+g_{A}=g_{\chi}+g_{Y}-g_{L_{Y}}$. Since (33) yields $g_{\chi}$ $=-\rho-g_{C}=-\rho-g_{Y}$, one gets $-g_{\mu}=g_{A}+\rho+g_{L_{Y}}$. Plugging these results in the first expression of $-g_{\mu}$, we obtain the following Bernoulli differential equation: $\dot{L}_{Y}=(\delta(1-\alpha) / \beta) L_{Y}^{2}-\rho L_{Y}$. In order to transform this equation into a first-order linear differential equation, we consider the new variable $z=1 / L_{Y}$, which implies $\dot{z}=-\dot{L}_{Y} / L_{Y}^{2}$. The differential equation becomes $\dot{z}=\rho z-\delta(1-\alpha) / \beta$, whose solution is $z=e^{\rho t}\left[z_{0}-\delta(1-\alpha) / \beta \rho\right]+\delta(1-\alpha) / \beta \rho$. Replacing $z$ by $1 / L_{Y}$ leads to $L_{Y}=\frac{1}{e^{\rho t}\left[1 / L_{Y 0}-\delta(1-\alpha) / \beta \rho\right]+\delta(1-\alpha) / \beta \rho}$. Using the transversality condition $\lim _{t \longrightarrow+\infty} \mu A=0$, one can show that $L_{Y}$ immediately jumps to its steady-state level:

$$
L_{Y}=\beta \rho / \delta(1-\alpha)
$$

Indeed, using (35) it turns out that the transversality condition is only satisfied when $L_{Y}=$ $L_{Y 0}=\beta \rho / \delta(1-\alpha)$.

The optimal level of $L_{Y}$ results from an arbitrage in the allocation of labor between production and research activities. The heuristic argument is the following. Suppose a marginal increase of labor in production, $\Delta L_{Y t}=1$, at date $t$. This leads to an increase in production and thus in consumption: $\Delta Y_{t}=\Delta C_{t}=\beta Y_{t} / L_{Y t}$. Since $C_{t}=(1-\alpha) Y_{t}$, one gets $\Delta C_{t}=\beta C_{t} /(1-\alpha) L_{Y t}$, which yields the following increase in utility: $\Delta U_{t}=\Delta C_{t} / C_{t}=\beta /(1-\alpha) L_{Y t}$. Assume now $\Delta L_{A t}=1$, at date $t$. This leads to an increase in knowledge, $\Delta A_{s}$, and thus in net production: $\Delta Y_{s}=\left(\partial Y_{s} / \partial A_{s}-x_{s}\right) \Delta A_{s}$, for all $s \geq t$. Since $\partial Y_{s} / \partial A_{s}=Y_{s} / A_{s}$, and $x_{s}=\alpha Y_{s} / A_{s}$, one gets $\Delta Y_{s}=(1-\alpha) Y_{s} \Delta A s / A_{s}$. Moreover, $A_{s}=A_{0} e^{\int_{0}^{s} \delta L_{A u} d u}$, thus $d A_{s}=A_{s} \delta d L_{A t}=\delta A_{s}$, for all $s \geq t$. This yields $\Delta Y_{s}=\delta(1-\alpha) Y_{s}$. Since $\Delta Y_{s}=\Delta C_{s}$ and $C_{s}=(1-\alpha) Y_{s}$, one gets $\Delta C_{s}=\delta C_{s}$.

The increase in the instantaneous utility at $s$ is thus $\delta$. Finally, since $\int_{0}^{+\infty} e^{-\rho t} d t=1 / \rho$, we see from (10) that the increase in the intertemporal utility is equal to $\delta / \rho$. Equating both increases in the intertemporal utility leads to $L_{Y}=\beta \rho / \delta(1-\alpha)$.

ii) Computation of $\zeta$.

The solution for equation (40) is $\zeta=e^{\theta t}\left(\int_{0}^{t} \omega e^{-(\rho+\theta) s} d s+\zeta_{0}\right)$. Moreover, the transversality condition associated to $Z$ writes

$$
\lim _{t \longrightarrow+\infty} \zeta Z=\lim _{t \longrightarrow+\infty} e^{\theta t}\left[\int_{0}^{t} \omega e^{-(\rho+\theta) s} d s+\zeta_{0}\right]\left[X_{0}+\int_{0}^{t} P_{s} e^{\theta(s-t)} d s\right]=0 .
$$

We obtain $\zeta_{0}=\int_{0}^{+\infty}(-\omega) e^{-(\rho+\theta) s} d s$, which gives $\zeta=e^{\theta t} \int_{t}^{+\infty}(-\omega) e^{-(\rho+\theta) s} d s=e^{-\rho t} \int_{t}^{+\infty}(-\omega) e^{-(\rho+\theta)(s-t)} d$ 
$=e^{-\rho t} \int_{0}^{+\infty}(-\omega) e^{-(\rho+\theta) u} d u$. Finally, we get

$$
\zeta=-\omega e^{-\rho t} /(\rho+\theta)
$$

$\zeta$ is the discounted value at $t=0$ of the social cost of one unit of carbon emitted at date $t$, expressed in terms of utility. This expression can be linked to the value of the optimal carbon tax at date $t$, measured in final good, in Proposition 1: $\tau^{o}=[\omega(1-\alpha) /(\rho+\theta)] Y=-\zeta e^{\rho t}(1-\alpha) Y$.

iii) Computation of $L_{Q}$.

Using (42), (36) becomes $-\mu \delta A+\omega e^{-\rho t} h^{\eta}(1-\eta) R^{\eta} L_{Q}^{-\eta} /(\rho+\theta)=0$. Using (33), (35) and (41), we get $\mu \delta A=\delta e^{-\rho t} / \rho$. Plugging this result into the preceding one, we get (11).

iv) Computation of $R$.

Using (37), (42) and (11), we obtain $R=\frac{\gamma}{\chi_{0} e^{\rho t}+B}$, in which $B=\frac{(1-\alpha) \omega h}{\rho+\theta}\left[1-\eta\left(\frac{\rho \omega(1-\eta)}{\delta(\rho+\theta)}\right)^{(1-\eta) / \eta}\right]$. Since we have assumed $[\rho \omega(1-\eta) / \delta(\rho+\theta)]^{1 / \eta}<1$ at the beginning of this appendix, then $B>0$.

We compute $\chi_{0}$ using the constraint $\int_{0}^{+\infty} R_{t} d t=S_{0}$. We have $S_{0}=\int_{0}^{+\infty} \frac{\gamma}{\chi_{0} e^{\rho t}+B} d t=$ $\int_{0}^{+\infty} \frac{\gamma e^{-\rho t}}{\chi_{0}+B e^{-\rho t}} d t$. Consider the new variable $u=\chi_{0}+B e^{-\rho t}$, which gives $d u=-\rho B e^{-\rho t} d t$. We have $S_{0}=\int_{\chi_{0}+B}^{\chi_{0}} \frac{-\gamma}{\rho B} \frac{d u}{u}=\frac{-\gamma}{\rho B} \ln \left(\frac{\chi_{0}}{\chi_{0}+B}\right)$. From this equation, one obtains $\chi_{0}=B /\left(e^{\frac{B \rho S_{0}}{\gamma}}-1\right)$. Finally, we get $g_{R t}^{o}=\frac{-\rho}{1+\left(e^{B \rho S_{0} / \gamma}-1\right) e^{-\rho t}}$.

v) Computation of $Q$ and $P$.

Plugging (11) into $Q=(h R)^{\eta} L_{Q}^{1-\eta}$, one gets $Q=\left(\frac{\rho \omega(1-\eta)}{\delta(\rho+\theta)}\right)^{(1-\eta) / \eta} h R$.

Then, using $P=h R-Q$, we have $P=\left[1-\left(\frac{\rho \omega(1-\eta)}{\delta(\rho+\theta)}\right)^{(1-\eta) / \eta}\right] h R$.

vi) Computation of $x$.

(1) can be rewritten as $Y=(A x) x^{\alpha-1} L_{Y}^{\beta} R^{\gamma}$. Since $A x=\alpha Y$ and using (41), we get $x=\alpha^{1 /(1-\alpha)}(\beta \rho / \delta(1-\alpha))^{\beta /(1-\alpha)} R^{\gamma /(1-\alpha)}$.

vii) Computation of growth rates.

The growth rates directly follow from the log-differentiation of the preceding results.

In summary, one gets:

$$
\begin{gathered}
L_{Y}^{o}=\beta \rho / \delta(1-\alpha), \\
L_{Q t}^{o}=\left[\frac{\rho \omega(1-\eta)}{\delta(\rho+\theta)}\right]^{1 / \eta} h R_{t}^{o}, \\
L_{A t}^{o}=1-L_{Y}^{o}-L_{Q t}^{o},
\end{gathered}
$$




$$
R_{t}^{o}=\frac{\gamma}{\chi_{0} e^{\rho t}+B}
$$

where $\chi_{0}=B /\left(e^{\frac{B \rho S_{0}}{\gamma}}-1\right)$ and $B=\frac{(1-\alpha) \omega h}{\rho+\theta}\left[1-\eta\left(\frac{\rho \omega(1-\eta)}{\delta(\rho+\theta)}\right)^{(1-\eta) / \eta}\right]$,

$$
\begin{gathered}
Q_{t}^{o}=\left(\frac{\rho \omega(1-\eta)}{\delta(\rho+\theta)}\right)^{(1-\eta) / \eta} h R_{t}^{o}, \\
P_{t}^{o}=\left[1-\left(\frac{\rho \omega(1-\eta)}{\delta(\rho+\theta)}\right)^{(1-\eta) / \eta}\right] h R_{t}^{o}, \\
g_{A t}^{o}=\delta L_{A t}^{o}, \\
g_{R t}^{o}=g_{L_{Q t}}^{o}=g_{Q_{t}}^{o}=g_{P_{t}}^{o}=\frac{-\rho}{1+\left(e^{\frac{B \rho S_{0}}{\gamma}}-1\right) e^{-\rho t}}, \\
g_{Y t}^{o}=g_{A t}^{o}+(\gamma /(1-\alpha)) g_{R t}^{o} .
\end{gathered}
$$

\section{Appendix 2: Welfare in the no-CCS case}

When no CCS technology is available, maximizing welfare leads to the following results (recall that we denote by $X_{t}^{o \varnothing}$ the optimal level of any variable $X_{t}$ in this case):

$L_{Y}^{o \varnothing}=\beta \rho / \delta(1-\alpha), L_{A}^{o \varnothing}=1-\beta \rho / \delta(1-\alpha), R_{t}^{o \varnothing}=\frac{\gamma}{\chi_{0}^{\varnothing} e^{\rho t}+B^{\varnothing}}, g_{R}^{o \varnothing}=\frac{-\rho}{1+\left(e^{\frac{B^{\varnothing} \rho S_{0}}{\gamma}}-1\right) e^{-\rho t}}$, $g_{A}^{o \varnothing}=\delta L_{A}^{o \varnothing}, g_{Y}^{o \varnothing}=\delta L_{A}^{o \varnothing}+(\gamma /(1-\alpha)) g_{R}^{o \varnothing}$, where $\chi_{0}^{\varnothing}=\frac{B^{\varnothing}}{e^{\left(B^{\varnothing} \rho S_{0} / \gamma\right)}-1}$ and $B^{\varnothing}=(1-\alpha) \omega h /(\rho+\theta)$.

Since $B<B^{\varnothing}$, we have $g_{R t}^{o}<g_{R t}^{o \varnothing}$.

\section{Appendix 3: Equilibrium in the decentralized economy}

Here also, we drop time subscripts for notational convenience.

i) Computation of $L_{Y}$

In this paper, we focus on climate policy and its impacts on the economy. Hence we assume that research is optimally funded; in other words, we assume that both subsidies to research, $s$ and $\sigma$, are set at their optimal levels. As in the standard case, the optimal level for the subsidy to the demand for intermediate goods, $s$, is $1-\alpha$. This can be shown as follows. Equation (3) shows that the marginal cost of $x_{i}$ is equal to 1 . Thus, the socially optimal price paid by the final sector, $p_{i}(1-s)$, must be equal to 1 . From (23), the monopoly price is $p_{i}=1 / \alpha(>1)$. Hence, we have $(1-s) / \alpha=1$, that is, $s=1-\alpha$.

The optimal value of the subsidy to research $\sigma$ is obtained in what follows.

Equation (18), in which $p_{i}(1-s)=1$ (from (23)), can be rewritten $Y=A x / \alpha$. Since $Y=C+A x$, one gets $C=(1-\alpha) Y$, as it is the case at the social optimum. 
From (15) and (26), we have $r=\rho+g_{C}=g_{V}+\frac{\pi^{m}+\sigma}{V}$, where $g_{C}=g_{Y}$.

From (27) and (19), after log-differentiation, we get $g_{V}=g_{w}-g_{A}=g_{Y}-g_{L_{Y}}-g_{A}$. Moreover, from (19), (25) and (27), we obtain $\pi^{m} / V=\delta(1-\alpha) A x L_{Y} / \alpha \beta Y$; since $A x=\alpha Y$, we get $\pi^{m} / V=\delta(1-\alpha) L_{Y} / \beta$. Plugging these two results into the expression of $r$ given above yields $\rho=-g_{L_{Y}}-g_{A}+\delta(1-\alpha) L_{Y} / \beta+\sigma / V$. It is now obvious that, if $\sigma / V=g_{A}=\delta L_{A}$, the previous equation becomes the following Bernoulli differential equation $\dot{L}_{Y}=(\delta(1-\alpha) / \beta) L_{Y}^{2}-\rho L_{Y}$. This equation is identical to the equation obtained in Appendix 1 (Section i). We thus solve it in the same way, only this time we use the transversality condition of the household's program. One can show that $L_{Y}$ immediately jumps to its steady-state level:

$$
L_{Y}=\beta \rho / \delta(1-\alpha)
$$

ii) Computation of $L_{Q}, Q$ and $P$.

From (19), (21) and (43), we have $Y \delta(1-\alpha) / \rho=(\tau+\lambda)(1-\eta)\left(h R / L_{Q}\right)^{\eta} /(1-\varphi)$. This yields

$$
L_{Q}=\left[\frac{(\tau+\lambda) \rho(1-\eta)}{(1-\varphi) \delta(1-\alpha) Y}\right]^{1 / \eta} h R
$$

Plugging (44) into (6), we get

$$
Q=\left[\frac{(\tau+\lambda) \rho(1-\eta)}{(1-\varphi) \delta(1-\alpha) Y}\right]^{(1-\eta) / \eta} h R
$$

Finally, (45) and (5) yield

$$
P=\left[1-\left(\frac{(\tau+\lambda) \rho(1-\eta)}{(1-\varphi) \delta(1-\alpha) Y}\right)^{(1-\eta) / \eta}\right] h R
$$

iii) Computation of $R$.

Basically, $R$ is obtained from (20). In order to express $R$ as a function of time and of the climate policy, we need to rewrite three elements of this equation. First, $L_{Q} / h R$ is obtained from (44). Secondly, using (15) in which $g_{C}=g_{Y}$, we get $Y=Y_{0} e^{e_{0}^{t}\left(r_{u}-\rho\right) d u}$. Finally, from (16), we have $p_{R}=p_{R 0} e^{\int_{0}^{t} r_{u} d u}$. Plugging these three results into (20) yields $R=\frac{\gamma}{\left(p_{R 0} / Y_{0}\right) e^{\rho t}+G}$, where $G=\frac{h \tau}{Y}-\eta h\left(\frac{\rho(1-\eta)}{(1-\varphi) \delta(1-\alpha)}\right)^{\frac{1-\eta}{\eta}}\left(\frac{\tau+\lambda}{Y}\right)^{\frac{1}{\eta}}$. Since $\tau / Y$ and $\lambda / Y$ are assumed constant, $G$ is constant. Hence using the condition $\int_{0}^{+\infty} R_{t} d t=S_{0}$ and the method used in Appendix 1 (Section iv), one gets:

$$
R=\frac{\gamma}{\psi_{0} e^{\rho t}+G}
$$


where $\psi_{0}=G /\left(e^{\frac{G \rho S_{0}}{\gamma}}-1\right)$.

iv) Computation of the rates of growth.

The growth rates directly follow from the log-differentiation of the preceding results. We obtain

$$
\begin{gathered}
g_{A}=\delta\left[1-\frac{\beta \rho}{\delta(1-\alpha)}-\left[\frac{(\tau+\lambda) \rho(1-\eta)}{(1-\varphi) \delta(1-\alpha) Y}\right]^{1 / \eta} h R\right] \\
\text { and } g_{R}=g_{L_{Q}}=g_{Q}=g_{P}=\frac{-\rho}{1+\left(e^{\frac{G \rho S_{0}}{\gamma}}-1\right) e^{-\rho t}} .
\end{gathered}
$$

Finally, we know that $x_{i} \equiv x$ (see equation (24)) and $Y=A x / \alpha$. Replacing $x$ by its value in (1) gives $Y=\alpha^{\alpha /(1-\alpha)} A L_{Y}^{\beta /(1-\alpha)} R^{\gamma /(1-\alpha)}$. Thus we have

$$
g_{Y}=g_{A}+(\gamma /(1-\alpha)) g_{R}
$$

v) Impact of carbon tax.

In order to analyze the impact of a change in $\tau / Y$ on the economy, one has to study its impact on $G$. One can easily see that $G \geq 0$ if and only if

$\lambda_{t} \leq \eta^{-\eta}\left[\rho(1-\eta) / Y_{t}(1-\varphi) \delta(1-\alpha)\right]^{\eta-1} \tau_{t}^{\eta}-\tau_{t}$ - see equation (29). In particular, if $\tau_{t}>0$ and $\lambda_{t}=0$, then $G>0$, that is, with the carbon tax alone, the growth rate of resource extraction is higher than its value in the absence of climate policy, $-\rho$.

One gets: $(1 / h) \frac{\partial G}{\partial(\tau / Y)}=1-\left(\frac{\left(\tau_{t}+\lambda_{t}\right) \rho(1-\eta)}{Y_{t}(1-\varphi) \delta(1-\alpha)}\right)^{(1-\eta) / \eta}$, which is positive, since we assume $0 \leq\left(\tau_{t}+\lambda_{t}\right) / Y_{t} \leq(1-\varphi) \delta(1-\alpha) / \rho(1-\eta)$. Then, using equations (28)-(30), and (45), (46), (49) and (50), the results described in Proposition 2 follow.

vi) Impact of the subsidy to sequestered carbon.

We have seen that $G<0$ if and only if $\lambda_{t}>\eta^{-\eta}\left[\rho(1-\eta) / Y_{t}(1-\varphi) \delta(1-\alpha)\right]^{\eta-1} \tau_{t}^{\eta}-\tau_{t}$. In particular, if $\lambda_{t}>0$ and $\tau_{t}=0$, then $G<0$, which means that, with the subsidy alone, the extraction growth rate is lower than its value in the absence of climate policy, $-\rho$. More generally, it is straightforward that $\partial G / \partial\left(\lambda_{t} / Y_{t}\right)$ is negative; for this reason, $\partial g_{R t} / \partial\left(\lambda_{t} / Y_{t}\right)$ is negative. As in Subsection v), the results described in Proposition 3 follow.

\section{References}

Acemoglu D, Aghion P, Bursztyn L, Hemous D (2012) The Environment and Directed Technical Change. American Economic Review 102(1):131-66

Aghion P, Howitt P (1998) Endogenous Growth Theory. The MIT Press 
Amigues JP, Lafforgue G, Moreaux M (2011) Optimal CCS and air capture from heterogeneous energy consuming sectors. LERNA working paper 11.16 .350

André FJ, Smulders S (2004) Energy use, endogenous technical change and economic growth. Mimeo

Ayong le Kama A, Fodha M, Lafforgue G (2009) Optimal Carbon Capture and Storage Policies. LERNA working paper 09.24.300

Barro RJ, Sala-i-Martin X (2003) Endogenous Growth Theory. The MIT Press

Copeland BR, Taylor ST (2004) Trade, Growth and the Environment. Journal of Economic Literature, American Economic Association 42(1):7-71

Dasgupta PS, Heal GM (1979) Economic Theory and Exhaustible Resources. Cambridge Economic Handbooks

Dasgupta PS, Heal GM, Stiglitz J (1981) The Taxation of Exhaustible Resources, NBER Working paper $\mathrm{n}^{\circ} 436$

Edenhofer O, Held H, Bauer N (2005) A Regulatory Framework for Carbon Capturing and Sequestration Within the Post-Kyoto Process. In E.S. Rubin, D.W. Keith and C.F. Gilboy (Eds.), Proceedings of 7th International Conference on Greenhouse Gas Control Technologies. Volume 1: Peer-Reviewed Paper and Plenary Presentations, IEA Greenhouse Gas Programme, Cheltenham, UK

Farzin YH, Tahvonen O (1996) Global Carbon Cycle and the Optimal Time Path of a Carbon Tax, Oxford Economic Papers, New Series 48(4):515-536

Gaudet G (2007) Natural Resource Economics under the Rule of Hotelling. Canadian Journal of Economics 40(4):1033-1059

Gerlagh R (2011) Too Much Oil. CESifo Economic Studies 57(1):79-102

Gerlagh R (2006) ITC in a global growth-climate model with CCS: The value of induced technical change for climate stabilization. The Energy Journal, Special issue on endogenous technological change and the economics of atmospheric stabilization 223-240

Gerlagh R, Kverndokk S, Rosendahl KE (2008) Linking Environmental and Innovation Policy. FEEM, Nota di Lavoro 53

Gerlagh R, van der Zwaan BCC (2006) Options and instruments for a deep cut in CO2 emissions: Carbon capture or renewables, taxes or subsidies? The Energy Journal 27:25-48

Gerlagh R, Liski M (2012) Carbon Prices for the Next Thousand Years. CESifo Working Paper Series No. 3855

Golombek R, Greaker M, Kittelsen SAC, Rogeberg O, Aune FR (2011) Carbon Capture and Storage Technologies in the European Power Market. The Energy Journal 32(3):209-238

Golosov R, Hassler J, Krusell P, Tsyvinski A (2011) Optimal Taxes on Fossil Fuels in General Equilibrium. NBER Working Paper No. 17348

Goulder LH, Mathai K (2000) Optimal $\mathrm{CO}_{2}$ Abatement in the Presence of Induced Technological Change. Journal of Environmental Economics and Management 39:1-38

Gradus R, Smulders S (1993) The Trade-Off between Environmental Care and Long-Term Growth-Pollution in Three Prototype Growth Models. Journal of Economics 58(1):25-51

Grimaud A (1999) Pollution Permits and Sustainable Growth in a Schumpeterian Model. Journal of Environmental Economics and Management 38:249-266

Grimaud A, Lafforgue G, Magné B (2011) Climate Change Mitigation Options and Directed Technical Change: A Decentralized Equilibrium Analysis. Resource and Energy Economics 33(4):938-962

Grimaud A, Rouge L (2008) Environment, Directed Technical Change and Economic Policy. Environmental and Resource Economics 41:439-463 
Groth C, Schou P (2007) Growth and Non-Renewable Resources: The Different Roles of Capital and Resource Taxes. Journal of Environmental Economics and Management 53(1):8098

Hoel M, Jensen S (2010) Cutting Costs of Catching Carbon. Intertemporal effects under imperfect climate policy. Research Department of Statistics Norway Discussion Papers 639

Hoel M, Kverndokk S (1996) Depletion of Fossil Fuels and the Impacts of Global Warming. Resource and Energy Economics 18:115-136

IPCC (2005) Special Report on Carbon dioxide Capture and Storage. Contribution of Working Group III, Report of the Intergovernmental Panel on Climate Change, Cambridge University Press, Cambridge, UK

Jepma C, Hauck D (2011) The Economics of Carbon Capture and Storage: An Update. International Review of Environmental and Resource Economics 4(3-4):221-260

Kalkuhl M, Edenhofer O, Lessmann K (2012) The Role of Carbon Capture and Sequestration Policies for Climate Change Mitigation. CESifo Working Paper 3834

Lafforgue G, Magné B, Moreaux M (2008) Energy Substitutions, Climate Change and Carbon Sinks. Ecological Economics 67:589-597

Lontzek S, Rickels W (2008) Carbon Capture and Storage and the Optimal Path of the Carbon Tax. Kiel Working Papers 1475

Narita D (2009) Economic Optimality of CCS Use: A Resource-Economic Model. Kiel Working Papers 1508

Nordhaus WD (1994) Managing the Global Commons: The Economics of Climate Change. MIT Press, Cambridge, MA

Popp D (2006) ENTICE-BR: The Effects of Backstop Technology R\&D on Climate Policy Models. Energy Economics 28:188-222

Ricci F (2007) Channels of Transmission of Environmental Policy to Economic Growth: A Survey of the Theory. Ecological Economics 60:688-699

Rickels W (2011) The Role of Sequestration Costs with a Ceiling on Atmospheric Carbon Concentration. Kiel Working Paper 1702

Schou P (2000) Polluting non-renewable resources and growth. Environmental and Resource Economics 16:211-227

Schou P (2002) When environmental policy is superfluous: growth and polluting resources. Scandinavian Journal of Economics 104:605-620

Sinclair P (1992) High does nothing and rising is worse: carbon taxes should keep declining to cut harmful emissions. The Manchester School 60(1):41-52

Sinn HW (2008) Public Policies Against Global Warming: a Supply Side Approach. International Tax and Public Finance 15:360-394

Smulders S, Gradus R (1996) Pollution abatement and long-term growth. European Journal of Political Economy 12(3):505-532

Stiglitz J (1974) Growth with Exhaustible Natural Resources, Review of Economic Studies 41:123-152

Stokey N (1998) Are There Limits to Growth?, International Economic Review 39(1):1-31

Stollery KR (1998) Constant Utility Paths and Irreversible Global Warming. Canadian Journal of Economics, 31 (3):730-742

Tahvonen O (1997) Fossil Fuels, Stock Externalities, and Backstop Technology. Canadian Journal of Economics XXX 4a:855-874

Ulph A, Ulph D (1994) The optimal time path of a carbon tax. Oxford Economic Papers 46:857-868 
van der Ploeg F, Withagen C (2012) Is There Really a Green Paradox? Journal of Environmental Economics and Management, forthcoming

van der Zwaan BCC, Gerlagh R (2009) Economics of geological $\mathrm{CO}_{2}$ storage and leakage. Climatic Change 93:285-309

Withagen C (1994) Pollution and Exhaustibility of fossil fuels. Resource and Energy Economics 16:235-242. 